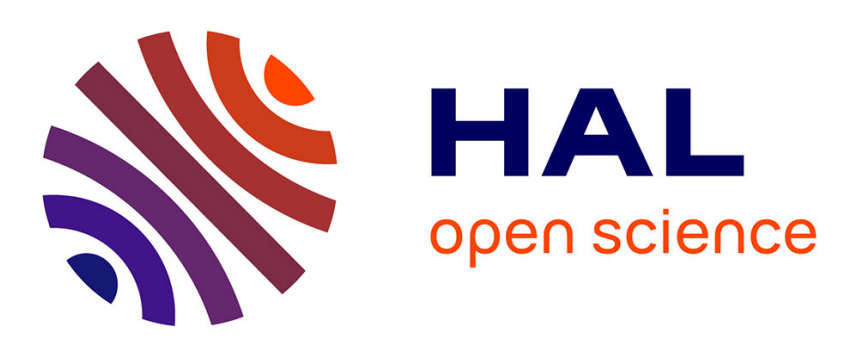

\title{
PI3-kinase promotes TRPV2 activity independently of channel translocation to the plasma membrane.
} Aubin Penna, Véronique Juvin, Jean Chemin, Vincent Compan, Michael Monet, François-A Rassendren

\section{To cite this version:}

Aubin Penna, Véronique Juvin, Jean Chemin, Vincent Compan, Michael Monet, et al.. PI3-kinase promotes TRPV2 activity independently of channel translocation to the plasma membrane.. Cell Calcium, 2006, 39 (6), pp.495-507. 10.1016/j.ceca.2006.01.009 . inserm-00320745

\section{HAL Id: inserm-00320745 https://www.hal.inserm.fr/inserm-00320745}

Submitted on 11 Sep 2008

HAL is a multi-disciplinary open access archive for the deposit and dissemination of scientific research documents, whether they are published or not. The documents may come from teaching and research institutions in France or abroad, or from public or private research centers.
L'archive ouverte pluridisciplinaire HAL, est destinée au dépôt et à la diffusion de documents scientifiques de niveau recherche, publiés ou non, émanant des établissements d'enseignement et de recherche français ou étrangers, des laboratoires publics ou privés. 


\title{
PI3-KINASE PROMOTES TRPV2 ACTIVITY INDEPENDENTLY OF CHANNEL TRANSLOCATION TO THE PLASMA MEMBRANE
}

\author{
Aubin Penna ${ }^{1}$, Véronique Juvin ${ }^{1}$, Jean Chemin ${ }^{2}$, Vincent Compan ${ }^{1}$, Michael Monet ${ }^{3}$ and \\ François-A. Rassendren ${ }^{1}$
}

1 Department of Molecular Pharmacology,

2 Department of Physiology,

Institut de Génomique Fonctionnelle

CNRS UMR 5203, Montpellier, France

INSERM U661, Montpellier, France

Université Montpellier I, Montpellier, France

Université Montpellier II, Montpellier, France

141, rue de la Cardonille 34396 Montpellier cedex France

3 Laboratoire de Physiologie Cellulaire

INSERM EMI-0228

Université de Lille 1,

59655 Villeneuve d'Ascq cedex, France

Address correspondence to: F. Rassendren, Department of Molecular Pharmacology, Institut de Génomique Fonctionnelle, 141, rue de la Cardonille, 34396 Montpellier cedex, France Tel:+33 499619978 - Fax: +33 499619901 - E-mail: far@igh.cnrs.fr 


\begin{abstract}
Cellular or chemical activators for most transient receptor potential channels of the vanilloid sub-family (TRPV) have been identified in recent years. A remarkable exception to this is TRPV2, for which cellular events leading to channel activation are still a matter of debate. Diverse stimuli such as extreme heat or phosphatidylinositol-3 kinase (PI3-kinase) regulated membrane insertion have been shown to promote TRPV2 channel activity. However, some of these results have proved difficult to reproduce and may underlie different gating mechanisms depending on the cell type in which TRPV2 channels are expressed. Here, we show that expression of recombinant TRPV2 can induce cytotoxicity that is directly related to channel activity since it can be prevented by introducing a charge substitution in the pore forming domain of the channel, or by reducing extracellular calcium. In stably transfected cells, TRPV2 expression results in an outwardly-rectifying current that can be recorded at all potentials, and in an increase of resting intracellular calcium concentration that can be partly prevented by serum starvation. Using cytotoxicity as a read-out of channel activity and direct measurements of cell surface expression of TRPV2, we show that inhibition of the PI3-kinase decreases TRPV2 channel activity but does not affect the trafficking of the channel to the plasma membrane. It is concluded that PI3-kinase induces or modulates the activity of recombinant TRPV2 channels; in contrast to the previously proposed mechanism, activation of TRPV2 channels by PI3-kinase is not due to channel translocation to the plasma membrane.
\end{abstract}

\title{
1. Introduction
}

Extracellular calcium influx initiates essential intracellular signaling events leading to diverse functions such as secretion, gene expression, cell proliferation and differentiation or cell death [1]. In non-excitable cells, calcium influx is mostly mediated by ion channels that are gated by various intracellular second messengers or activated following depletion of intracellular calcium stores [2]. The molecular identity of most of these ion channels has been established in human as well as in different model organisms including C. elegans, Drosophila and mouse. These channels have been named TRP channels, since they are encoded by a large family of genes which codes for proteins that display strong structural homologies with the Drosophila TRP protein. Based on sequence homology, mammalian 
TRP genes have been further subdivided into seven classes including three main subfamilies called TRPC, TRPV and TRPM. Subsequent physiological studies have shown that TRP channels within the same subfamily also display functional homologies, based on their involvement in second messenger induced calcium influx, and in calcium signals implicating store operated channels [3].

All members of the TRP superfamily share the same membrane topology as voltagegated potassium channels; they have six hydrophobic domains thought to span the plasma membrane and an additional P-loop structure between the fifth and the sixth transmembrane segments that participates in the pore forming domain of the channel [4]. To date, all TRP channels that have been functionally expressed display cationic selectivity with calcium permeabilities ranging from high (TRPV6) to null (TRPM4 and TRPM5) [5].

The precise cellular functions of most TRP channels remain unresolved, due to the lack of specific pharmacological tools and to their complex mode of gating. Only in the case of TRPV proteins, have pharmacological agonists and cellular events leading to channel opening been characterized in some detail $[6,7]$.

Although TRPV1, 3 and 4 channels act unambiguously as cellular temperature sensors, the gating of endogenous TRPV2 by noxious heat is still a matter of debate. If TRPV2 is expressed in large diameter dorsal root ganglion neurons that also express capsaicin-insensitive heat activated channels [8], it is also present in numerous other tissues, especially in immune cells [9] where a primary physiological role as thermal sensor remains questionable. In non-neuronal cell lines such as pancreatic MIN6 or CHO cells, it has been proposed that TRPV2 channel activity might be regulated by growth factor signaling [10]. Growth factors present in serum appear to induce a dynamic and transient translocation of the TRPV2 channel from intracellular compartments to the plasma membrane through a PI3kinase dependent pathway $[10,11]$. Other TRPV2 activation mechanisms have also been proposed. In myocytes, TRPV2 channels behave as mechano- and osmo-gated channels and could be involved in the regulation of vascular tone or in myocyte degeneration $[12,13]$.

Our initial aim in this study was to further investigate growth factor-induced translocation of TRPV2 after transient expression in immortalized cell lines. To our surprise, we found that expression of mouse TRPV2 channels (mTRPV2) in HEK293 cells induced morphological alterations and cell death. These events could be prevented by reducing extracellular calcium concentration or when a mutant mTRPV2 channel carrying a charge substitution ( ${ }^{\mathrm{Glu}} 594$ to ${ }^{\mathrm{Lys}} 594$ ) in the pore forming domain was expressed in HEK cells, indicating that cellular toxicity was directly linked to mTRPV2 channel activity. TRPV2- 
mediated cytotoxicity could also be prevented by inhibition of PI3-kinase with chemical inhibitors or following serum deprivation. In stably transfected CHO cells, we found that mTRPV2 but not the pore mutant channels displayed a constitutive activity that resulted in increased resting calcium levels, events that could also be prevented by serum starvation. Finally, using different experimental approaches we show that surface expression of TRPV2 is not regulated by PI3-kinase. Our data suggest that PI3-kinase regulates TRPV2 gating but has no role in the trafficking of the channel to the plasma membrane.

\section{Material and methods}

\subsection{Reagents and antibodies}

All chemicals were purchased from Sigma-Aldrich except for protease inhibitors that were from Roche. Culture media and reagents were obtained from Invitrogen.

Anti-flag biotinylated M2 monoclonal antibody (1:1000), Anti-flag M2 agarose beads and anti-flag HRP conjugated (WB: 1:8000, ELISA: 1:6000) were obtained from SigmaAldrich. Anti-HA 12CA5 monoclonal antibody (1:150) was from Roche. Anti-VRL-1 polyclonal antibody (1:100) was from Oncogene. Streptavidin-Texas Red (1:1000) was from Amersham. Cy3-conjugated secondary antibodies were purchased from Jackson ImmunoResearch (anti-rabbit, 1:1000; anti-mouse 1:2000). Streptavidin-HRP (1:50 000) was from Pierce.

\section{2 cDNA cloning, epitope tagging and site directed mutagenesis}

Human TRPV2 cDNA was isolated from a CF-PAC1 pancreatic cell line library by high stringency screening using the human EST clone BG765155 as a probe. Two independent full-length clones were isolated and sequenced. Mouse TRPV2 was cloned by RT-PCR from thymus single strand cDNA. All clones were analyzed by sequencing.

Flag tag sequence (DYKDDDDK) or HA tag sequence (YPYDVPDYA) were introduced in frame by overlapping PCR as described previously [14]. Flag tags were inserted either at the N-termini of mouse and human TRPV2 channels or in the first extracellular loop of the mouse TRPV2 channel between residues $\mathrm{S}^{420}$ and $\mathrm{K}^{421}$. HA tag was inserted at a similar position in an N-terminally flag tagged human TRPV2 channel (between residues $\mathrm{A}^{419}$ and 
$\mathrm{A}^{420}$ ). Amino acid substitutions were generated by using oligonucleotide-directed mutagenesis as previously described [15]. All constructs were verified by DNA sequencing.

\subsection{Cell culture and transfection}

Human embryonary kidney cells (HEK293), Chinese hamster ovary cells (CHO) were grown in DMEM/HEPES and F12 (HAM) nutrient mixture, respectively. All culture media were supplemented with $1 \%$ Glutamax-I, $100 \mathrm{IU} / \mathrm{ml}$ penicillin, $100 \mu \mathrm{g} / \mathrm{ml}$ streptomycin, and $10 \%$ fetal calf serum. DNA transfections were performed by using LipofectAMINE 2000 (Invitrogen) for HEK cells, or jetPEI (Qbiogene) for $\mathrm{CHO}$, according to instructions provided by the manufacturers. When indicated, cells were co-transfected with an EGFP-encoding plasmid and the channel-encoding plasmidat a ratio of $1 / 10$, the total amount of DNA was $1 \mu \mathrm{g}$. For stable cell line generation, $\mathrm{CHO}$ cells were transfected with mouse TRPV2 cDNA subcloned into pcDNA3 vector. After neomycin selection, monoclonal stable cells were isolated.

\subsection{Immunocytochemistry}

$12 \mathrm{~h}$ after transfection, cells were seeded on polyornithine-coated $25 \mathrm{~mm}$ glass coverslips and cultured for $24-36 \mathrm{~h}$ in the conditioned medium indicated in the figure legends. For classical indirect immunofluorescent microscopy, cells were fixed in $4 \%$ paraformaldehyde for 10 minutes, washed with a solution of $0.1 \mathrm{M}$ glycine, and then permeabilized using $0.05 \%$ Triton X100 for 5 minutes. Blocking of non-specific binding sites was performed by incubating cells with PBS containing 0.5\% BSA for 30 minutes. Cells were incubated with the primary antibody overnight at $4^{\circ} \mathrm{C}$. After PBS washes, fluorescent secondary antibody was added for 30 minutes at $37^{\circ} \mathrm{C}$. To visualize all the cells present on coverslips, cell nuclei were stained with Hoechst (1:1000, Sigma) for 1 minute at room temperature. After extensive washing coverslips were mounted and viewed with a Leica DMRA2 fluorescent microscope. For deconvolution and image reconstruction, images of fixed cells were processed with the Huygens Professional Software from Scientific Volume Imaging B.V using MLE algorithms.

For in vivo labelling, extracellular HA tagged hTRPV2 transfected cells were starved for 12 hours in medium containing $0.5 \%$ FCS, and then for an additional 3 hours in the complete absence of serum. When indicated, 10\% FCS was added for a further 15 minutes. 
Membrane expression of the channel was revealed by incubating cells with the anti-HA 12CA5 monoclonal antibody directly into the conditioned culture medium for 45 minutes at $37^{\circ} \mathrm{C}$. Cells were then washed with culture medium and PBS, fixed with $4 \%$ paraformaldehyde for 10 minutes, washed with a solution of $0.1 \mathrm{M}$ glycine, blocked with PBS containing $0.5 \%$ BSA for 30 minutes and then incubated with fluorescent secondary antibody as described previously. After washes, coverslips were mounted and viewed through an oil immersion 100X objective on a Leica DMRA2 fluorescent microscope.

\subsection{Cell counting and statistical analysis}

For quantitative analysis of GFP and double GFP/flag expression, cells were independently scored in five random fields through a $40 \mathrm{X}$ oil objective. All results were normalized to the total number of cells in the five fields (Hoechst positive cells). Because there is good evidence that $\mathrm{P} 2 \mathrm{X} 2$ does not induce cytotoxic changes $[16,17]$ results were normalized to the number of GFP fluorescent cells in GFP-P2X2 co-transfected cells.

Statistical analysis was performed with unpaired Student's $t$ test using GraphPad Prism, (GraphPad software, San Diego California) except for figure 4A for which a one-way ANOVA test was used. In all figures, the number $\mathrm{n}$ indicates independent experiments.

\subsection{Cytotoxicity assay}

Transfected living cells plated on glass coverslips were washed with PBS and stained for cell death with the Annexin-V-FLUOS staining kit (Roche) according to the manufacturer's instructions. Images were collected directly through a 20X dry objective on a Leica DMRA2 fluorescent microscope. For positive controls of cell death, P2X7 transfected cells were stimulated for $10 \mathrm{~min}$ with $300 \mu \mathrm{M}$ ATP at $37^{\circ} \mathrm{C}$ in the presence of propidium iodate.

\subsection{Intracellular calcium measurements}

For Fluo-4 calcium measurements, parental and stable expressing $\mathrm{CHO}$ cells were plated in poly-ornithine coated 96-well plates at a density of $10^{5}$ cells per well. Plates were washed three times in Hank's Balanced Salt Solution (HBSS) containing : $142 \mathrm{mM} \mathrm{NaCl}$, $5.6 \mathrm{mM} \mathrm{KCl}, 1 \mathrm{mM} \mathrm{MgCl} 2,2 \mathrm{mM} \mathrm{CaCl} 2,0.34 \mathrm{mM} \mathrm{Na}_{2} \mathrm{HPO}_{4}, 0.44 \mathrm{mM} \mathrm{KH} \mathrm{KO}_{4}, 10 \mathrm{mM}$ 
HEPES, and $5.6 \mathrm{mM}$ glucose. The osmolarity and $\mathrm{pH}$ of this solution were adjusted to 310 mOsm and 7.4, respectively. Cell were then incubated in HBSS supplemented with $2.5 \mathrm{mM}$ probenecid (SIGMA), $100 \mu \mathrm{g} / \mathrm{ml}$ pluronic acid (Molecular Probes) and 1 $\mu \mathrm{M}$ Fluo4-AM (Molecular Probes) for $1 \mathrm{~h}$ at $37^{\circ} \mathrm{C}$. Following the incubation, cells were washed twice with HBSS and kept in 50 $\mu 1$ of HBSS. Intracellular calcium measurements were performed on a fluid handling integrated fluorescence plate reader (FlexStation II, Molecular Devices). The fluo4 fluorescence was read at excitation and emission wavelengths of 494 and $525 \mathrm{~nm}$ respectively, from the bottom of the plate at $0.5 \mathrm{~Hz}$ for 2 minutes. All experiments were performed at $30^{\circ} \mathrm{C}$. Each condition was performed in triplicate; for each well, fluorescence was integrated over a one minute period, expressed as a single value and the values for three wells of the same condition were averaged. Results were normalized to fluorescence values obtained in parental $\mathrm{CHO}$ cells under control conditions.

For $\mathrm{Ca}^{2+}$ measurements using Fura-2 AM, CHO culture medium was replaced by an HBSS solution. When a $\mathrm{Ca}^{2+}$ free medium was required, $\mathrm{CaCl}_{2}$ was omitted and replaced by equimolar $\mathrm{MgCl}_{2}$. Dye loading was achieved by transferring the cells into a standard HBSS solution containing $1 \mathrm{mM}$ Fura-2 AM (Calbiochem) for $40 \mathrm{~min}$ at $37^{\circ} \mathrm{C}$, then rinsing them three times with dye free solution. Intracellular $\mathrm{Ca}^{2+}$ was measured by an imaging system (Princeton). The glass coverslip was mounted in a chamber on an Olympus microscope equipped for fluorescence. Fura-2 fluorescence was excited at 340 and $380 \mathrm{~nm}$ and emitted fluorescence was measured at $510 \mathrm{~nm}$. The $\left[\mathrm{Ca}^{2+}\right]$ cyt concentration was derived from the ratio of the fluorescence intensities for each of the excitation wavelengths (F340/F380), and from the Grynkiewicz equation $(\mathrm{Kd}=224 \mathrm{nM}, \mathrm{Rmin}=0.18$, and $\mathrm{Rmax}=1.7)$. All recordings were made at $37^{\circ} \mathrm{C}$. The cells were continuously perfused with HBSS solution via a whole-chamber perfusion system. The flow rate of the whole-chamber perfusion system was set to $1 \mathrm{ml} / \mathrm{min}$ and the chamber volume was $500 \mu 1$. Results were expressed as mean \pm SEM. Plots were produced using Origin 5.0 (Microcal Software). Each experiment was repeated at least three times. The Turkey-Kramer test was used for statistical comparison of means and differences, $* * *$ indicates $\mathrm{P}<0.001$.

\subsection{Electrophysiological recordings}

For electrophysiological analysis, cells were plated at the density of $210^{5}$ cells per 35 $\mathrm{mm}$ culture dish. One to two days after plating, whole-cell currents were recorded at room temperature. Extracellular solution contained (in $\mathrm{mM}$ ): $150 \mathrm{NaCl}, 5 \mathrm{KCl}, 2 \mathrm{CaCl}_{2}, 1 \mathrm{MgCl}_{2}$ 
and 10 HEPES (pH adjusted to 7.35 with $\mathrm{NaOH}, 330 \mathrm{mOsm}$ ). Pipettes had a resistance of 1.5$3 \mathrm{M}$ when filled with a solution containing (in mM): $140 \mathrm{CsCl}, 10$ EGTA, 10 HEPES, $3 \mathrm{Mg}-$ ATP, $2 \mathrm{CaCl}_{2}$ and 0.6 GTP-Na (pH adjusted to 7.2 with $\mathrm{CsOH}, 315 \mathrm{mOsm}$ ). Recordings were performed using an Axopatch 200B amplifier (Molecular Devices). Holding potential was $-60 \mathrm{mV}$. Currents were recorded in response to $900 \mathrm{~ms}$ voltage ramps from -100 to $+100 \mathrm{mV}$ applied every 5 seconds. The sampling frequency for acquisition was $10 \mathrm{kHz}$ and data were filtered at $2 \mathrm{kHz}$. Data were analysed using pClamp9 (Molecular Devices) and Prism4 (GraphPad) software.

\subsection{Cell surface expression assay}

Cells were transfected in $35 \mathrm{~mm}$ dishes and six hours after transfection, the contents of each dish were divided into 4 wells of a 12-well plate. Assays were carried out $48 \mathrm{~h}$ after culture in the conditioned media indicated in the figure legend. Cells were fixed in $4 \%$ paraformaldehyde for $5 \mathrm{~min}$ and either permeabilized using $0.1 \%$ Triton-X100 or not. Cells were incubated in blocking solution (PBS/1\% fetal calf serum) for $30 \mathrm{~min}$ and then with an anti-flag M2 antibody directly coupled with HRP for $1 \mathrm{~h}$ at room temperature. Luminescence was measured using Supersignal ELISA femto Maximum sensitivity substrate (Pierce) and quantified in a Victor 2 luminometer (Perkin Elmer). Surface expression was calculated as the ratio between the signal obtained for non-permeabilized cells (representing the amount of protein at the cell surface), and the signal obtained for permeabilized cells (which represents the total cellular amount of proteins).

\subsection{Plasma membrane protein biotinylation, immunoprecipitation and Western-blotting}

Following the same serum starvation and/or stimulation as for in vivo labelling, transfected HEK293 cells grown on polyornithine coated dishes were washed twice in ice-cold PBS containing $0.1 \mathrm{mM} \mathrm{CaCl}_{2}$ and $1 \mathrm{mM} \mathrm{MgCl}_{2}$ (PBS-CM). Cell surface expressed proteins were labelled using $1 \mathrm{mg} / \mathrm{ml}$ sulfo-NHS-Biotin (Pierce) for $30 \mathrm{~min}$ at $4{ }^{\circ} \mathrm{C}$ in biotinylation buffer (10mM TEA, $\left.2 \mathrm{mM} \mathrm{CaCl}_{2}, 150 \mathrm{mM} \mathrm{NaCl}, \mathrm{pH} 9\right)$. Cells were washed twice with PBS-CM containing $0.1 \%$ BSA ( 5 min) and once with PBS. Lysis was performed by scraping cells in $500 \mu 1$ of lysis buffer $(20 \mathrm{mM}$ Hepes $\mathrm{pH} 7.4,100 \mathrm{mM} \mathrm{NaCl}, 5 \mathrm{mM}$ EDTA, $1 \%$ Triton X100, $2 \mu \mathrm{g} / \mathrm{ml}$ pepstatin, $10 \mu \mathrm{g} / \mathrm{ml}$ bestatin, $2 \mu \mathrm{g} / \mathrm{ml}$ leupeptin, $0.5 \mu \mathrm{g} / \mathrm{ml}$ aprotinin and $30 \mu \mathrm{M}$ Pefabloc) and passed five times through a $26 \mathrm{G}$ needle. After $30 \mathrm{~min}$ of solubilization at $4{ }^{\circ} \mathrm{C}$ 
under agitation, lysates were centrifuged $\left(16000 \mathrm{~g}, 10 \mathrm{~min}, 4^{\circ} \mathrm{C}\right)$ and supernatant collected.

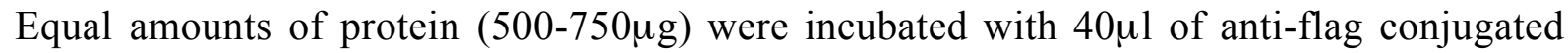
agarose beads (Sigma) overnight at $4^{\circ} \mathrm{C}$ on a rotating wheel. Beads were washed three times $\left(5 \mathrm{~min}\right.$ at $4^{\circ} \mathrm{C}$ ) in $20 \mathrm{mM}$ Hepes $\mathrm{pH} 7.4,150 \mathrm{mM} \mathrm{NaCl}, 10 \%$ glycerol and $0,1 \%$ Triton-X100. Proteins were eluted by incubation with $20 \mu \mathrm{l}$ of $200 \mathrm{mM}$ glycine $\mathrm{pH} 2.2$, neutralized with $4 \mu \mathrm{l}$ of $1 \mathrm{M}$ TrisHCl pH 8.5 and diluted in Laemmli buffer. Proteins were resolved by SDS-PAGE, transferred to nitrocellulose membranes and visualized using either Streptavidin-HRP or antiflag-HRP, and ECL+ detection kit (Amersham).

In each experiment, a flag-tagged intracellular protein was expressed as permeabilization control during labelling procedure and immuno-depletion of all samples was checked by SDS-PAGE on protein of the flow-through.

\section{Results}

\subsection{Transient expression of $m T R P V 2$ results in morphological alterations and cytotoxicity}

To monitor membrane expression of TRPV2 channels, HEK cells were transfected with plasmids encoding either mTRPV2 channel or the ATP-gated channel P2X2, the latter being used as a control. Both channels carried an extracellular flag epitope to detect proteins expressed at the plasma membrane [15]. As illustrated in Figure 1A, cells transfected with mTRPV2, identified following anti-flag immunostaining, presented marked morphological alterations. Typically, mTRPV2 transfected cells displayed a spread out morphology with vacuolated cytoplasm and numerous filopodia. In contrast, P2X2 transfected and nontransfected cells displayed almost round morphology, compact cytoplasm and occasionally one or two cellular processes. These morphological characteristics of mTRPV2 expressing cells are typical of cellular necrosis, and suggested that expression of TRPV2 could have cytotoxic effects. We therefore determined whether the number of mTRPV2-transfected cells was reduced 48 hours after transfection compared to control P2X2-flag transfected cells. In all experiments an EGFP plasmid was co-expressed either with P2X2-flag or mTRPV2-flag cDNAs. Protein expression was visualized using flag immunoreactivity and GFP fluorescence. Because P2X2 receptors have no known cytotoxic effect, all results were normalized to the number of GFP fluorescent cells counted amongst GFP-P2X2-flag transfected cells. As shown in figure 1B, when HEK cells were co-transfected with P2X2flag and GFP, $62.9 \% \pm 2.8(\mathrm{n}=7)$ of cells showed flag immunostaining as compared to cells 
expressing GFP, indicating a higher transfection efficiency for GFP plasmids than for P2X2 cDNA. However, when cells were co-transfected with mTRPV2-flag and GFP, both the number of flag and GFP positive cells were reduced to $35.1 \% \pm 3.5(\mathrm{n}=6)$ and $73.5 \% \pm 4.2$, $(n=7)$, respectively. The decrease of both mTRPV2 and GFP positive cells suggested that mTRPV2 expression might have a cytotoxic effect. Alternatively, co-expression of mTRPV2 and GFP could have lower efficiency. To test between these two hypotheses, we performed a cytotoxicity assay based on propidium iodate (PI) staining. HEK cells were transfected either with mTRPV2-flag, P2X2-flag as negative control or with P2X7 as positive control; P2X7 has indeed been shown to induce cell death following its activation with extracellular ATP [18]. As shown in figure 1C, 48 hours after transfection no apparent cell necrosis could be visualized in HEK cells expressing P2X2-flag receptors. However cells expressing mTRPV2flag displayed strong PI staining similar to that obtained in P2X7 expressing cells after stimulation with $300 \mu \mathrm{M}$ ATP. These results indicate that expression of mTRPV2 channel in HEK cells induces cell death, presumably through necrosis, since no evidence for apoptosis was detected (not shown).

\subsection{An mTRPV2 permeation mutant prevents cell death}

Different causes such as constitutive activity leading to intracellular calcium overload, plasmid poisoning or improper protein folding, might be responsible for mTRPV2-induced cytotoxicity. To test whether cell death could be a consequence of channel activity, we introduced a charge substitution, Glu to Lys at position 594, in the pore-forming domain of mTRPV2-flag channels. In TRPV1, an identical substitution [E636K] in the permeation pathway leads to non-functional channels presumably by affecting cation permeation through the pore [19]. As shown in figure 2A, mTRPV2-flag[E594K] showed normal membrane localization when expressed in HEK cells and no difference in cell morphology was observed between P2X2-flag and mTRPV2-flag[E594K] transfected cells. The number of GFP positive cells expressing mutant TRPV2 channels or P2X2 receptors were not statistically different: $67.1 \% \pm 3.7$ and $66.1 \% \pm 5.3(n=9)$, respectively. Importantly, total numbers of GFP positive cells were not different, indicating an equal efficiency of transfection of the mTRPV2-flag[E594K] and P2X2-flag cDNAs. To confirm the lack of cytotoxicity of the mTRPV2-flag[E594K] mutant, PI staining was performed $48 \mathrm{~h}$ after transfection, as described above. Figure 2C clearly shows that no significant PI signal occurred in P2X2-flag or mTRPV2-flag[E594K] transfected cells, whereas ATP-stimulated P2X7 expressing cells 
display strong staining. Taken together these results strongly suggest that mTRPV2-induced cell death is linked to channel activity rather than non-specific toxicity.

\subsection{Cellular toxicity is linked to mTRPV2 channel activity and intracellular calcium overload}

Although cellular mechanisms leading to TRPV2 channel gating are still controversial, one hypothesis is that TRPV2 channel activity is controlled by growth factors through a PI3kinase-dependent signaling pathway [10]. We therefore tested whether inhibition of PI3kinase either by serum starvation or by chemical inhibitors could reduce mTRPV2-induced cytotoxicity. In these experiments, cells were co-transfected with EGFP and either P2X2-flag, mTRPV2-flag or mTRPV2-flag[E594K]. Culture media were conditioned as described (see legend of figure 3). 48 hours after transfection, flag immunostaining was performed and the number of GFP and double GFP/flag positive cells was independently quantified (see legend of figure 1). In normal culture conditions (figure 3A), the number of mTRPV2-transfected cells positive for both GFP and flag was reduced to $35.2 \% \pm 4.1$ ( $\mathrm{n}=6)$ compared to $62.4 \% \pm$ $3.3(\mathrm{n}=6)$ and $64.1 \% \pm 5.4(\mathrm{n}=6)$ for P2X2-flag and mTRPV2-flag[E594K], respectively. Cells transfected with wild type mTRPV2 also showed a significant reduction of GFP expressing cells, to $74.3 \% \pm 4.9(\mathrm{n}=6)$, further demonstrating that mTRPV2 expression is directly linked to cytotoxicity. However, reducing the serum to $0.5 \%$, or adding $25 \mu \mathrm{M}$ LY294002 protected mTRPV2-flag expressing cells from death (figure 3B and C); the proportions of GFP/flag positive cells were $70.9 \% \pm 7.6(n=3)$ in $0.5 \%$ serum and $55.8 \% \pm$ $1.9(n=3)$ in complete medium supplemented with $25 \mu$ M LY294002. In these conditions, the numbers of cells expressing wild type mTRPV2 were not significantly different from those of cells expressing either mTRPV2-flag[E594K] or P2X2-flag (see figure 3B, C).

These data suggest that serum factors, through a PI3-kinase pathway, may promote a constitutive activity of TRPV2 channels that results in a sustained calcium entry through the channel, intracellular calcium overload and cell death. To test this hypothesis, calcium concentration in the culture medium was reduced to a sub-millimolar range by addition of 1.5mM EGTA to normal culture medium; mTRPV2 cytotoxicity was assayed as previously described. As shown in figure 3D, reduction of extracellular calcium protected cells from mTRPV2-induced cytotoxicity; the proportion of cells expressing mTRPV2 $(54.6 \% \pm 5.2$, $\mathrm{n}=3$ ) was not significantly different from that of cells expressing mTRPV2-flag[E594K] 
$(60.7 \% \pm 8.5, \mathrm{n}=3)$ or P2X2-flag $(65.7 \% \pm 4.3, \mathrm{n}=3)$, cultured in similar conditions. Reduction of extracellular calcium did not affect the relative proportion of cells expressing mTRPV2-flag[E594K] or P2X2-flag as compared to control conditions (compare figures 3A and D). These results show that mTRPV2-induced cell death is likely due to a constitutive channel activity and calcium overload.

\section{4 mTRPV2 channels are constitutively activated in $\mathrm{CHO}$ cells}

To further confirm that mTRPV2 channels are constitutively activated and responsible for a sustained calcium influx, electrophysiological recordings and intracellular calcium measurements were performed in CHO cells stably expressing the channel. In these cells, no apparent cytotoxicity of mTRPV2 was observed, conceivably because of a lower level of expression of the channel compared to levels achieved by transient transfection. In addition, the expected lack of activity of the mTRPV2[E594K] mutant was investigated. Currents were recorded in the whole cell configuration by applying voltage ramps from $-100 \mathrm{mV}$ to $+100 \mathrm{mV}$, either in parental or stably transfected CHO cells. As shown in figure $4 \mathrm{~A}$, in such conditions, parental cells display almost no current at negative potentials and a small conductance for very depolarized potentials, whereas in stably mTRPV2 transfected cells, an outwardly-rectifying conductance that reversed near $-5 \mathrm{mV}$ was consistently recorded (figure 4B). Current densities at $-50 \mathrm{mV}$ for parental and TRPV2 expressing cells were respectively, $0.9 \mathrm{pA} / \mathrm{pF} \pm 0.5(\mathrm{n}=21)$ and $4.9 \mathrm{pA} / \mathrm{pF} \pm 1.5(\mathrm{n}=10)$, clearly indicating that mTRPV2 expression leads to a significant functional activity at resting membrane potential $(\mathrm{p}<0.01$, Student's $t$ test) (figure 4, panels D and E). Furthermore, 2-aminoethoxydiphenyl borane (2APB) and ruthenium red (RR), molecules that respectively activate or inhibit mTRPV2 channel function [20], did not alter the endogenous currents recorded in parental CHO cells. In contrast, currents recorded in TRPV2 expressing cells were strongly potentiated by $100 \mu \mathrm{M}$ 2-APB whereas $10 \mu \mathrm{M}$ ruthenium red completely inhibited both basal and 2-APB stimulated currents; these currents thus showed all the hallmarks of TRPV2 channels. These results also demonstrate that at the resting membrane potential, TRPV2 channels are likely to be open. When the same analysis was performed using CHO cells transfected with the mTRPV2[E594K] mutant, current densities at $-50 \mathrm{mV}$ were $(1.76 \mathrm{pA} / \mathrm{pF} \pm 1.5, \mathrm{n}=18)$ and not statistically different from those of parental cells ( $\mathrm{p}=0.29$, Student's $t$ test). This was equally true in the presence of $100 \mu \mathrm{M} 2-\mathrm{APB}$, although a small current could still be observed (figure 
4C) this indicates that the charge substitution introduced in the pore-forming loop had indeed silenced mTRPV2 channels.

Because mTRPV2 channels are open at the resting membrane potential we investigated whether this constitutive activity had any effect on resting intracellular calcium concentration. Using the calcium indicator Fura-2, intracellular calcium levels were measured in CHO cells stably expressing mTRPV2 and parental cells. CHO-mTRPV2 cells displayed a significantly higher resting calcium concentration (135.1 $\mathrm{nM} \pm 2.6)$ compared to parental cells $(100.1 \mathrm{nM} \pm 1.6)(\mathrm{p}<0.001$, Student's $t$ test $)$. When cells were incubated in the absence of extracellular calcium, intracellular calcium levels of CHO-mTRPV2 cells were not different from parental cells indicating that, in resting conditions, mTRPV2 constitutive activity induces sustained calcium influx. We next evaluated whether the enhanced resting intracellular calcium levels in CHO-mTRPV2 cells could be modulated by serum starvation. These experiments were performed in a 96-well plate assay as described in the methods section. In control conditions, CHO-mTRPV2 cells displayed a significant increase in basal fluorescence compared to parental cells $(391.8 \% \pm 31.7, \mathrm{n}=6,2$ experiments, $\mathrm{p}<0.001$, Student's $t$ test ). This increase was reduced to $179.6 \% \pm 9$ ( $\mathrm{n}=6,2$ experiments) upon overnight serum starvation ( $\mathrm{p}<0.05$, Student's $t$ test, compared to CHO-mTRPV2 cells in control conditions). No difference in the basal fluorescence of control cells was observed in parental CHO cells between control and starved conditions, indicating that serum starvation had no effect on dye loading. Taken together, these results clearly indicate that in resting conditions mTRPV2 channels display a constitutive activity that results in increased intracellular calcium levels. In addition, they also support the proposal that serum factors promote mTRPV2 channel activity.

\subsection{TRPV2 channels are not dynamically translocated to the plasma membrane}

Previous work on the mechanism of TRPV2 channel activation has provided evidence that these channels are constitutively active upon insertion in the plasma membrane, an event induced by a dynamic translocation of the channel from intracellular compartments to the membrane, triggered by growth factors through a PI3-kinase dependent pathway [10]. We therefore evaluated whether the lack of cytotoxicity observed following serum starvation or inhibition of PI3-kinase activity was due to a reduction of the number of TRPV2 channels in the plasma membrane. We took advantage of the presence of an extracellular tag in the mTRPV2 protein to directly quantify the amount of channels present at the cell surface, using 
a cellular based assay $[15,21]$. HEK cells were transfected with either mTRPV2-flag or P2X2-flag and kept in various conditioned media (10\% serum, 0.5\% serum, $10 \%$ serum and $100 \mathrm{nM}$ wortmannin) as described in figure 3. 48 hours after transfection, cells were vigorously washed to remove cellular debris and dead cells before quantification of channel expression at the cell surface. As shown in figure 5A, in control conditions (10\% serum) 72.2 $\% \pm 4,(\mathrm{n}=7)$ of mTRPV2 is expressed at the cell surface, similarly to P2X2 $(69.7 \% \pm 5.4$, $\mathrm{n}=3$ ). When PI3-kinase activity was reduced, the amount of TRPV2 expressed at the plasma membrane was not statistically affected, since it represented $74.1 \% \pm 4.1(\mathrm{n}=3)$ and $60.4 \% \pm 2$ $(\mathrm{n}=3)$ in $0.5 \%$ serum or $100 \mathrm{nM}$ wortmannin, respectively. The total amount of protein did not vary between the different experimental conditions (data not shown). This strongly suggests that PI3-kinase is not involved in the regulated trafficking of TRPV2 to the plasma membrane. Additional experiments were also performed on untagged mTRPV2 using CHO cells stably expressing mTRPV2 channels, in conditions as close as possible to previously published conditions [10]. Cells were kept either in normal cell culture conditions or serum starved for 12 hours; in the latter case a 15 minutes serum stimulation was performed prior to cell fixation. Membrane expression of mTRPV2 channels was examined using immunofluorescent staining confocal microscopy and image deconvolution. As shown in figure $5 \mathrm{~B}$, in normal culture conditions, mTRPV2 is predominantly expressed at the plasma membrane; a similar pattern of expression is observed after serum starvation or after starvation and serum re-introduction. These results indicate that (i) the extracellularly located flag epitope is not responsible for a constitutive membrane localization of mTRPV2 channels and, (ii) serum starvation does not affect the subcellular expression of mTRPV2 channels, as previously proposed [10].

Because TRPV2-mediated cell death is observed only in around 50\% of the total TRPV2 transfected cell population (see figure1B), we investigated whether, in the remaining TRPV2-transfected cells, serum was responsible for surface expression of TRPV2 channels. In this case, to look for possible species differences, we used an extracellular flag and HAtagged human TRPV2 channel (flag-hTRPV2-HA) expressed in HEK cells. Membrane expression of the channel was monitored following in vivo immunostaining. 36 hours after transfection cells were serum-starved overnight then stimulated with or without $10 \%$ serum for 15 minutes, the anti-HA antibody being incubated in the culture medium prior to cell fixing. As shown in figure $5 \mathrm{C}$, in both culture conditions flag-hTRPV2-HA channels were present at the plasma membrane without any noticeable difference. Similar observations were made following growth factor (IGF-1) stimulation (data not shown). To further confirm these 
results, we performed membrane protein biotinylation in HEK cells. To verify that the extracellular tag did not impair protein translocation, different human and mouse TRPV2 constructs were used: double flag/HA tagged hTRPV2 with or without the [E599K] mutation (homologous position of E594 in mTRPV2), N-terminal flag-hTRPV2 and mTRPV2flag[E594K]. The P2X2-flag construct was used as positive control of biotinylation. Effects of serum were tested after 16 hours of serum deprivation and 15 minutes re-introduction. As shown in figure 6D, almost identical levels of biotinylated TRPV2 proteins were observed in serum-starved and serum stimulated conditions. This was true for all constructs tested, indicating that neither extracellular tags nor pore mutations interfered with the trafficking of the channels to the plasma membrane. Altogether, our results show that PI3-kinase is not involved in a dynamic insertion of the TRPV2 channels in the plasma membrane of transfected cells.

\section{Discussion}

Among the six TRPV channels, the cellular mechanisms leading to TRPV2 gating still remain poorly characterized. Different reports have shown that heat above $52^{\circ} \mathrm{C}$, hypo-osmolarity, membrane stretch or PI3-kinase regulated membrane insertion of the channel could be implicated in the regulation of TRPV2 activity [10, 12, 13, 22]. However, some of these observations have proved difficult to reproduce. For example, translocation of recombinant TRPV2 channels in HEK cells has been questioned [23]. Similarly, in TRPV2 transfected CHO cells, we have been unable to observe any increase in intracellular calcium concentration or channel activity following a hypo-osmotic challenge (unpublished observation) or membrane stretch (Dr. E. Honoré, personal communication), as reported [12, 13]. In this study, we found that transient expression of TRPV2 channels in immortalized cell lines did result in cell death. It could be argued that the flag insertion in TRPV2 we have used here may have impaired channel trafficking. This is however unlikely for different reasons. First, we did not observe any differences in the membrane localization of untagged TRPV2 and flag-tagged channels (compare figure 6 panels B and C). Second, we chose to use the flag insertion site in the first extracellular loop (between the first and the second transmembrane domain), based on immunofluorescence and biochemical data showing no differences compared with the untagged channel (see figure 6). Third, an extracellular HA epitope has been introduced at a similar location in the TRPV1 channel [24] without affecting its trafficking nor its biophysical properties. Fourth, functional analysis of TRPV2-flag channels 
shows no difference in response to 2-APB stimulation as compared to untagged channels (data not shown). Altogether, this strongly argues against an impaired trafficking of TRPV2flag channels. Instead, several lines of evidence strongly suggest that the cytotoxicity observed in TRPV2-expressing cells is directly linked to channel activity. The most compelling argument comes from the fact that cytotoxicity and channel activity were both inhibited when a single amino acid substitution (glutamate to lysine) was introduced in the pore forming region of the channel, despite a clear localization of mutant channels at the plasma membrane.

Activity-dependent cytotoxic effects of TRPV2 channels are also supported by a pharmacological approach. Inhibition of PI3-kinase activity by serum deprivation or chemically with LY294002 or wortmannin reduced mTRPV2-mediated cell death. Because these two pharmacological treatments are well known pro-apoptotic signals [25], it is therefore unlikely that they might induce cell survival per se. The most straightforward explanation is that the activity of TRPV2 channels is linked to growth factor signaling and PI3-kinase pathways, as previously proposed [10].

Our results suggest that in normal culture conditions (10\% serum), serum factors promote a basal activity of TRPV2 that results in intracellular calcium overload and cell death. Indeed, chelating extracellular calcium with EGTA promotes survival of TRPV2 expressing cells, and CHO cells stably expressing mTRPV2 show a higher resting intracellular calcium concentration that returns to normal levels upon serum starvation. Calcium overload with subsequent cell death mediated by TRP channel activation has been reported for other members of this super-family. Sustained activation of TRPV1 by capsaicin results in apoptotic death of sensory neurons or thymocytes [26, 27]. Similarly, enhanced activity of TRPM2 or TRPL channels in relation to cellular dysfunctions are associated with cell death and retinal degeneration, respectively [28, 29]. It is therefore conceivable that in pathophysiological situations, constitutive activation of TRPV2 could result in calciummediated cell damage.

TRPV2-mediated cell death might be due to the loss of a negative regulatory mechanism, such as internalization or phosphorylation, which could turn off channel activation. Alternatively, over-expression of TRPV2 channels may overcome endogenous regulatory mechanisms, resulting in constitutive channel activity. In this case, only cells with high levels of expressed channels would be expected to show a cytotoxic phenotype; this may explain the residual viability of TRPV2-expressing cells that we observed. Such a differential regulation of recombinant TRP channels as a function of the expression levels has been 
demonstrated in the case of the TRPV6 channel which is not activated by active store depletion at high levels of expression [30]. Interestingly, cytotoxicity was not observed in cells expressing the calcium permeable ATP-gated P2X2 channel . In culture, extracellular ATP constitutively released from cells can reach concentrations sufficient to activate P2X receptors [31]. Even though $\mathrm{P} 2 \mathrm{X}$ receptors are expressed at very high levels, their constitutive activation is not cytotoxic because their desensitization occurs during prolonged activation [32]. This further supports the hypothesis that in transfected cells, TRPV2-mediated cytotoxicity results from constitutive channel activity due to the absence of a regulatory component of the channel.

Early studies of the regulation of TRPV2 activity suggested that the channel has a constitutive activity and that a PI3-kinase-dependent plasma membrane insertion of the protein, and its subsequent removal is the main mechanism by which cells regulate channel activity [10]. However, this membrane translocation of recombinant TRPV2 channel has been mainly illustrated in CHO cells. In this regard, one possible cause of TRPV2-mediated cytotoxicity could be that this regulated trafficking of TRPV2 channel is impaired in our cell lines either because of an enhanced forward trafficking or because of a lack of internalization, resulting in intracellular calcium overload and cell death. This is unlikely for two main reasons. First, we have investigated in three different cell lines HEK, CHO and COS (data not shown), a possible serum or PI3-kinase dependent trafficking of TRPV2 channels, but we were unable to visualize any change in the membrane expression of the channel. The probability is very low that each of these three different cell lines lacks the appropriate regulatory component necessary for a regulated trafficking of TRPV2 channels. In addition, TRPV2-mediated cell death could be reduced by serum starvation or by pharmacological inhibition of PI3-kinase activity, without any change in surface expression of TRPV2 channels. One can argue that PI3-kinase dependent translocation only occurs in a subset of cells that will subsequently die because of this enhanced surface expression of the channel. However, in stably TRPV2-transfected CHO cells, where cytotoxicity was absent presumably because of a lower expression level of the channels or reduced PI3-kinase activity, we could not detect any change in the membrane expression of the channel after serum starvation (see figure 6B). Secondly, membrane expression of TRPV2 was monitored using different experimental approaches such as direct luminometric quantification, membrane protein biotinylation or immunofluorescence on fixed and living cells. In all these experiments, we clearly demonstrate that PI3-kinase is not involved in the regulation of the trafficking of 
TRPV2 channels to the plasma membrane, whereas in identical conditions, PI3-kinase activity is directly correlated to cytotoxicity. Taken together, these results clearly show that PI3kinase is not involved in the trafficking of TRPV2 channels, but rather regulates channel gating. TRPV2 insertion at the plasma membrane might be regulated by other mechanisms. Incidentally, it has been proposed that calcium could be involved in such a dynamic regulation of TRPV2 channels [11]; by promoting TRPV2 channel activity and therefore calcium influx PI3-kinase could thus indirectly promote channel trafficking to the plasma membrane. In addition, a TRPV2 partner called RGA, has recently been identified by an interaction trap screening. Interaction of RGA with TRPV2 promotes its surface expression, in a protein kinase A dependent way [9]. This suggests that other intracellular pathways might regulate surface expression of TRPV2 channels. Dynamic trafficking of TRPV2 channels is therefore likely to be of physiological relevance, but further studies will be necessary to fully decipher the pathways involved.

In summary, our results demonstrate that activity of TRPV2 channels is dependent upon growth factor stimulation through a PI3-kinase pathway. However, our results do not support the hypothesis that this pathway functions by dynamic insertion of TRPV2 channel proteins into the plasma membrane. Rather, we propose that PI3-kinase promotes a constitutive TRPV2 channel activity that is normally under negative regulation, either by association with unknown partners or by distinct signaling crosstalk associated with the PI3kinase cascade. The loss of a regulatory mechanism leading to a constitutive and cytotoxic activity of TRPV2 channel is supported by the report that in myotubes from BIO 14.6 hamsters that are deficient in $\delta$-sarcoglycan, TRPV2 activity is increased and leads to myocyte degeneration [13]. As observed for other TRP channels [33], TRPV2 certainly belongs to signaling complexes of which certain components directly influence channel activity or trafficking. These modulations are likely to be important in immune cells where TRPV2 is highly expressed and where signaling complexes are known to be crucial for appropriate immune responses. The availability of cell lines endogenously expressing TRPV2 channels and of specific TRPV2 antagonists would clearly be useful tools to investigate normal gating and regulation of this channel.

\section{Acknowledgments}


We wish to thank Isabel Lefevre, Annmarie Surprenant and Jean-Philippe Pin for critical review of the manuscript, Dr Séverine Chaumont for her advice during the course of this study. A.P., V.J. and V.C. were supported by a studentship from Ministère de la Recherche et de la Technologie. A.P. was also supported by Association de la Recherche contre le Cancer. This work was supported by Fondation pour la Recherche Médicale. 


\section{References}

1. M.J. Berridge, M.D. Bootman, H.L. Roderick, Calcium signalling: dynamics, homeostasis and remodelling, Nat Rev Mol Cell Biol 4 (2003) 517-29.

2. A.B. Parekh, R. Penner, Store depletion and calcium influx, Physiol Rev 77 (1997) 901-30.

3. D.E. Clapham, L.W. Runnels, C. Strubing, The TRP ion channel family, Nat Rev Neurosci 2 (2001) 387-96.

4. T. Voets, B. Nilius, The pore of TRP channels: trivial or neglected?, Cell Calcium 33 (2003) 299-302.

5. $\quad$ N.D. Ullrich, T. Voets, J. Prenen, et al., Comparison of functional properties of the $\mathrm{Ca}(2+)-$ activated cation channels TRPM4 and TRPM5 from mice, Cell Calcium 37 (2005) 267-78.

6. M.J. Gunthorpe, C.D. Benham, A. Randall, J.B. Davis, The diversity in the vanilloid (TRPV) receptor family of ion channels, Trends Pharmacol Sci 23 (2002) 183-91.

7. B. Nilius, J. Vriens, J. Prenen, G. Droogmans, T. Voets, TRPV4 calcium entry channel: a paradigm for gating diversity, Am J Physiol Cell Physiol 286 (2004) C195-205.

8. S. Tamura, Y. Morikawa, E. Senba, TRPV2, a capsaicin receptor homologue, is expressed predominantly in the neurotrophin-3-dependent subpopulation of primary sensory neurons, Neuroscience 130 (2005) 223-8.

9. A.J. Stokes, C. Wakano, K.A. Del Carmen, M. Koblan-Huberson, H. Turner, Formation of a physiological complex between TRPV2 and RGA protein promotes cell surface expression of TRPV2, J Cell Biochem (2004).

10. M. Kanzaki, Y.Q. Zhang, H. Mashima, L. Li, H. Shibata, I. Kojima, Translocation of a calcium-permeable cation channel induced by insulin-like growth factor-I, Nat Cell Biol 1 (1999) 165-70.

11. K. Boels, G. Glassmeier, D. Herrmann, et al., The neuropeptide head activator induces activation and translocation of the growth-factor-regulated $\mathrm{Ca}(2+)$-permeable channel GRC, $\mathrm{J}$ Cell Sci 114 (2001) 3599-606.

12. K. Muraki, Y. Iwata, Y. Katanosaka, et al., TRPV2 is a component of osmotically sensitive cation channels in murine aortic myocytes, Circ Res 93 (2003) 829-38.

13. Y. Iwata, Y. Katanosaka, Y. Arai, K. Komamura, K. Miyatake, M. Shigekawa, A novel mechanism of myocyte degeneration involving the $\mathrm{Ca} 2+$-permeable growth factor-regulated channel, J Cell Biol 161 (2003) 957-67.

14. R. Stoop, S. Thomas, F. Rassendren, et al., Contribution of individual subunits to the multimeric P2X(2) receptor: estimates based on methanethiosulfonate block at T336C, Mol Pharmacol 56 (1999) 973-81.

15. S. Chaumont, L.H. Jiang, A. Penna, R.A. North, F. Rassendren, Identification of a trafficking motif involved in the stabilization and polarization of P2X receptors, J Biol Chem 279 (2004) 29628-38.

16. C. Virginio, A. MacKenzie, F.A. Rassendren, R.A. North, A. Surprenant, Pore dilation of neuronal P2X receptor channels, Nat Neurosci 2 (1999) 315-21.

17. A. MacKenzie, H.L. Wilson, E. Kiss-Toth, S.K. Dower, R.A. North, A. Surprenant, Rapid secretion of interleukin-1beta by microvesicle shedding, Immunity 15 (2001) 825-35.

18. A. Surprenant, F. Rassendren, E. Kawashima, R.A. North, G. Buell, The cytolytic P2Z receptor for extracellular ATP identified as a P2X receptor (P2X7), Science 272 (1996) 735-8.

19. C. Garcia-Martinez, C. Morenilla-Palao, R. Planells-Cases, J.M. Merino, A. Ferrer-Montiel, Identification of an aspartic residue in the P-loop of the vanilloid receptor that modulates pore properties, J Biol Chem 275 (2000) 32552-8.

20. H.Z. Hu, Q. Gu, C. Wang, et al., 2-aminoethoxydiphenyl borate is a common activator of TRPV1, TRPV2, and TRPV3, J Biol Chem 279 (2004) 35741-8.

21. D. Ma, N. Zerangue, Y.F. Lin, et al., Role of ER export signals in controlling surface potassium channel numbers, Science 291 (2001) 316-9.

22. M.J. Caterina, T.A. Rosen, M. Tominaga, A.J. Brake, D. Julius, A capsaicin-receptor homologue with a high threshold for noxious heat, Nature 398 (1999) 436-41. 
23. V.J. Bezzerides, I.S. Ramsey, S. Kotecha, A. Greka, D.E. Clapham, Rapid vesicular translocation and insertion of TRP channels, Nat Cell Biol 6 (2004) 709-20.

24. N. Garcia-Sanz, A. Fernandez-Carvajal, C. Morenilla-Palao, et al., Identification of a tetramerization domain in the $\mathrm{C}$ terminus of the vanilloid receptor, J Neurosci 24 (2004) 530714.

25. M.P. Wymann, M. Zvelebil, M. Laffargue, Phosphoinositide 3-kinase signalling--which way to target?, Trends Pharmacol Sci 24 (2003) 366-76.

26. C. Amantini, M. Mosca, R. Lucciarini, et al., Distinct thymocyte subsets express the vanilloid receptor VR1 that mediates capsaicin-induced apoptotic cell death, Cell Death Differ 11 (2004) 1342-56.

27. P.S. Chard, D. Bleakman, J.R. Savidge, R.J. Miller, Capsaicin-induced neurotoxicity in cultured dorsal root ganglion neurons: involvement of calcium-activated proteases, Neuroscience 65 (1995) 1099-108.

28. D. McHugh, R. Flemming, S.Z. Xu, A.L. Perraud, D.J. Beech, Critical intracellular Ca2+ dependence of transient receptor potential melastatin 2 (TRPM2) cation channel activation, J Biol Chem 278 (2003) 11002-6.

29. B. Minke, The TRP calcium channel and retinal degeneration, Adv Exp Med Biol 514 (2002) 601-22.

30. L. Yue, J.B. Peng, M.A. Hediger, D.E. Clapham, CaT1 manifests the pore properties of the calcium-release-activated calcium channel, Nature 410 (2001) 705-9.

31. G. Buell, A.D. Michel, C. Lewis, G. Collo, P.P. Humphrey, A. Surprenant, P2X1 receptor activation in HL60 cells, Blood 87 (1996) 2659-64.

32. J. Rettinger, G. Schmalzing, Desensitization masks nanomolar potency of ATP for the P2X1 receptor, J Biol Chem 279 (2004) 6426-33.

33. C. Montell, Physiology, phylogeny, and functions of the TRP superfamily of cation channels, Sci STKE 2001 (2001) RE1. 


\section{LEGENDS TO FIGURES}

\section{Figure 1: mTRPV2 induces morphological alterations and cytotoxicity in HEK}

transfected cells. (A) HEK cells were co-transfected with an EGFP encoding plasmid and either P2X2-flag or mTRPV2-flag constructs, the epitope being extracellularly localized. Immunostaining was performed on fixed and permeabilized cells using a biotinylated anti-flag antibody and streptavidin-Texas Red conjugate. Insets show GFP fluorescence used as transfection control. Note the difference in cell morphology between P2X2-flag and mTRPV2-flag transfected cells. (B) Quantification of cell number. Cells were co-transfected as in (A) and their numbers estimated by counting. Number of GFP expressing cells (GFP, grey bars) and double GFP/flag positive cells (GFP + flag, black bars) were normalized as described in material and methods. Results are presented as mean $\pm \operatorname{SEM}(\mathrm{n}=7)$ ***, $p<0.001$, Student's $t$ test. When mTRPV2 was co-transfected with GFP, a strong reduction of the number of both GFP expressing cells and GFP/mTRPV2 double positive cells was observed as compared to cells co-transfected with P2X2 and GFP. Note that the proportion of cell expressing GFP was always higher than double positive cells, indicating a higher efficiency of transfection with GFP . (C) Cytotoxicity was assessed by PI staining on HEK cells transfected either with mTRPV2-flag, P2X2-flag (negative control) or with P2X7 and stimulated with $300 \mu \mathrm{M}$ ATP (positive control). Insets show phase contrast pictures used to assess the total number of cells in each field. PI staining was observed only in mTRPV2-flag and in ATP stimulated P2X7 expressing cells, indicating that mTRPV2 induces cell death.

\section{Figure 2: mTRPV2 permeation mutant [E594K] is not cytotoxic in transfected HEK}

cells. HEK cells were co-transfected with an EGFP encoding plasmid and either P2X2-flag or the mTRPV2-flag[E594K] pore mutant constructs; experiments were performed as described for figure 1. (A) Immunostaining of HEK cells expressing mTRPV2[E594K] or P2X2 channels. No difference in cell morphology was observed between cells transfected with mTRPV2-flag[E594K] or P2X2-flag. Insets show GFP fluorescence used as transfection control. (B) Quantification of the number of cells: GFP positive (GFP, grey bars) and double positive for GFP and flag (GFP + flag, black bars). Note that in these experiments, $70 \%$ of cells co-expressed GFP and either channel. The numbers of cells expressing mTRPV2flag[E594K] or P2X2-flag were not significantly different. Results are presented as mean \pm SEM (n=9). ns, $p>0.05$, Student's $t$ test. (C) The cytotoxic effect of mTRPV2-flag[E594K], 
P2X2-flag (negative control) and P2X7 in cells stimulated with $300 \mu \mathrm{M}$ ATP (positive control) was assessed by PI staining in transfected HEK cells. Insets show phase contrast pictures used to determine the total number of cells in each field. PI staining is almost absent in P2X2-flag and mTRPV2-flag[E594K] transfected cells whereas present in HEK cells expressing P2X7 after ATP stimulation, suggesting that mTRPV2-induced cytotoxicity is due to its constitutive activity.

Figure 3 : mTRPV2 cytotoxicity is dependent on channel activity. HEK cells were cotransfected with EGFP and either P2X2-flag, mTRPV2-flag or mTRPV2-flag[E594K] encoding plasmids. $12 \mathrm{~h}$ after transfection, cells were grown for an additional $36 \mathrm{~h}$ in conditioned medium (10\% FCS $(A), 0.5 \%$ FCS $(B), 10 \%$ FCS supplemented with $25 \mu \mathrm{M}$ LY294002 (C), 10\% FCS supplemented with 1.5mM EGTA (D)). Immunostaining and cell quantification were performed as indicated (see legend of figure 1). Results are displayed as in figure 1: the number of GFP positive cells (grey bars) and double positive cells for GFP and flag (black bars) are normalized to the number of GFP positive cells in batches cotransfected with P2X2-flag and GFP; results are expressed as mean \pm SEM of at least three independent experiments. ns, $p>0.05 ;{ }^{*} p<0.05$ Student's $t$ test.

Irrespective of growth condition, the number of P2X2-flag or mTRPV2-flag[E594K] expressing cells was not statistically different. In contrast, the number of mTRPV2-flag expressing cells in normal culture conditions $(10 \% \mathrm{FCS})$ was significantly reduced compared to mTRPV2-flag[E594K] transfected cells (compare with figure 1). Note that in this case the number of GFP positive cells is also reduced (panel A). When serum was reduced to $0.5 \%$ (panel B), or when normal culture medium was supplemented with LY294002 (panel C) or EGTA (panel D), the numbers of cells expressing WT or the [E594K] mutant mTRPV2 channels are not significantly different, indicating a reduction in mTRPV2 activity.

\section{Figure 4 : mTRPV2 shows constitutive activity that is impaired by charge substitution}

introduced in the p-loop region. Whole cell recordings were performed in $\mathrm{CHO}$ cells either non transfected, stably expressing mTRPV2 or transiently transfected with the mTRPV2[E594K] mutant. Cells were held at $-60 \mathrm{mV}$ and voltage ramps from -100 to $+100 \mathrm{mV}(900 \mathrm{~ms}$, every $5 \mathrm{sec})$ were applied to evoke currents. (B) CHO-mTRPV2 cells express an outwardly rectifying current that is enhanced by $100 \mu \mathrm{M} 2-\mathrm{APB}$ and inhibited by $10 \mu \mathrm{M}$ ruthenium red (RR). This conductance is not present in parental cells (A) nor in cells expressing the mTRPV2[E594K] mutant (C). Current density analyses (D, E) show that 
TRPV2 channels are likely to be open at the resting membrane potential and suggest that CHO-mTRPV2 cells express either a limited number of channels or that the conductance of mTRPV2 is small. Results are means $\pm \mathrm{SEM},{ }^{* *} \mathrm{p}<0.01$, ns $\mathrm{p}>0.05$, student's $t$ test).

\section{Figure 5: Serum factors and PI3-kinase are not required for TRPV2 trafficking to the}

plasma membrane. (A) Direct quantification of TRPV2 surface expression by cellular Elisa. HEK cells were transfected with P2X2 or mTRPV2 constructs carrying an extracellular flag epitope. After $48 \mathrm{~h}$ of culture in a conditioned medium containing $10 \%, 0.5 \%$ FCS or $10 \%$ FCS and 100nM wortmannin, chemiluminescence assay was directly performed on fixed cells as described in material and methods. Results are expressed as mean \pm SEM of the ratio between signals from non permeabilized and permeabilized cells, giving a direct reading of the proportion of total cellular protein expressed at the plasma membrane. The same proportion of mTRPV2 channels was expressed at the cell surface regardless of the serum concentration or the presence of an inhibitor of PI3-kinase. Note that P2X2 and TRPV2 channels showed similar plasma membrane expression levels. (B) CHO cells stably expressing wild type mTRPV2 channel were serum starved, or not, for a total of $15 \mathrm{~h}$ as described in material and methods; cells were then stimulated with 10\% FCS for 15 minutes. mTRPV2 immunostaining was performed on fixed and permeabilized cells using an antiVR1L specific polyclonal antibody and Cy3 conjugated anti-rabbit antibody. Digital image restoration was performed as described in material and methods; images presented are representative slices through the middle of the cell. No difference in the membrane localization of mTRPV2 was observed between the different serum conditions. (D) Serum factors do not induce dynamic translocation of the TRPV2 channel at the plasma membrane of living HEK cells. After 36h of culture, flag-hTRPV2-HA HEK transfected cells were serum starved for a total of $15 \mathrm{~h}$; cells were then stimulated with $10 \%$ FCS for 15 minutes. Plasma membrane expression of the flag-hTRPV2-HA channel was visualized by in vivo labeling using an anti-HA 12CA5 monoclonal antibody as described in material and methods. As observed for for mTRPV2 expressed in CHO cells, flag-hTRPV2-HA expressed in HEK cells was always present at the plasma membrane, even after $15 \mathrm{~h}$ serum starvation. (E) HEK cells were transfected with different tagged TRPV2 or P2X2 constructs (as indicated) and subjected to the same serum starvation paradigm as in $(A)$. Membrane proteins were biotinylated; after flag immunoprecipitation, biotinylated proteins and total immunoprecipitated proteins were revealed with streptavidin-HRP or with an anti-flag-HRP 
antibody, respectively. Irrespective of epitope position, pore mutation, or serum starvation/stimulation, TRPV2 channels were consistently expressed at the plasma membrane. 
Figure 1

A

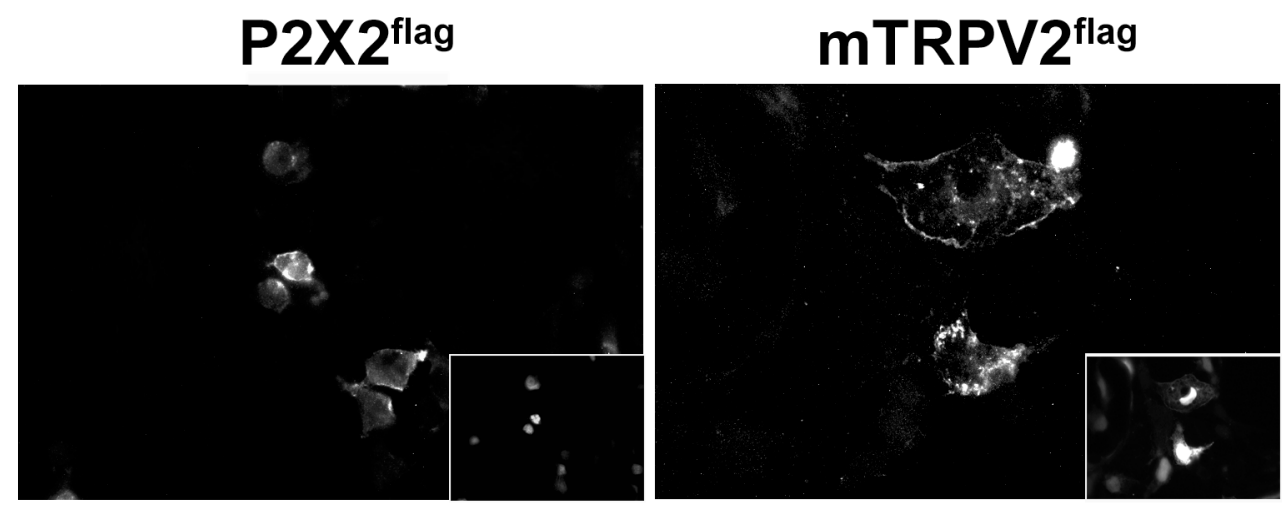

B

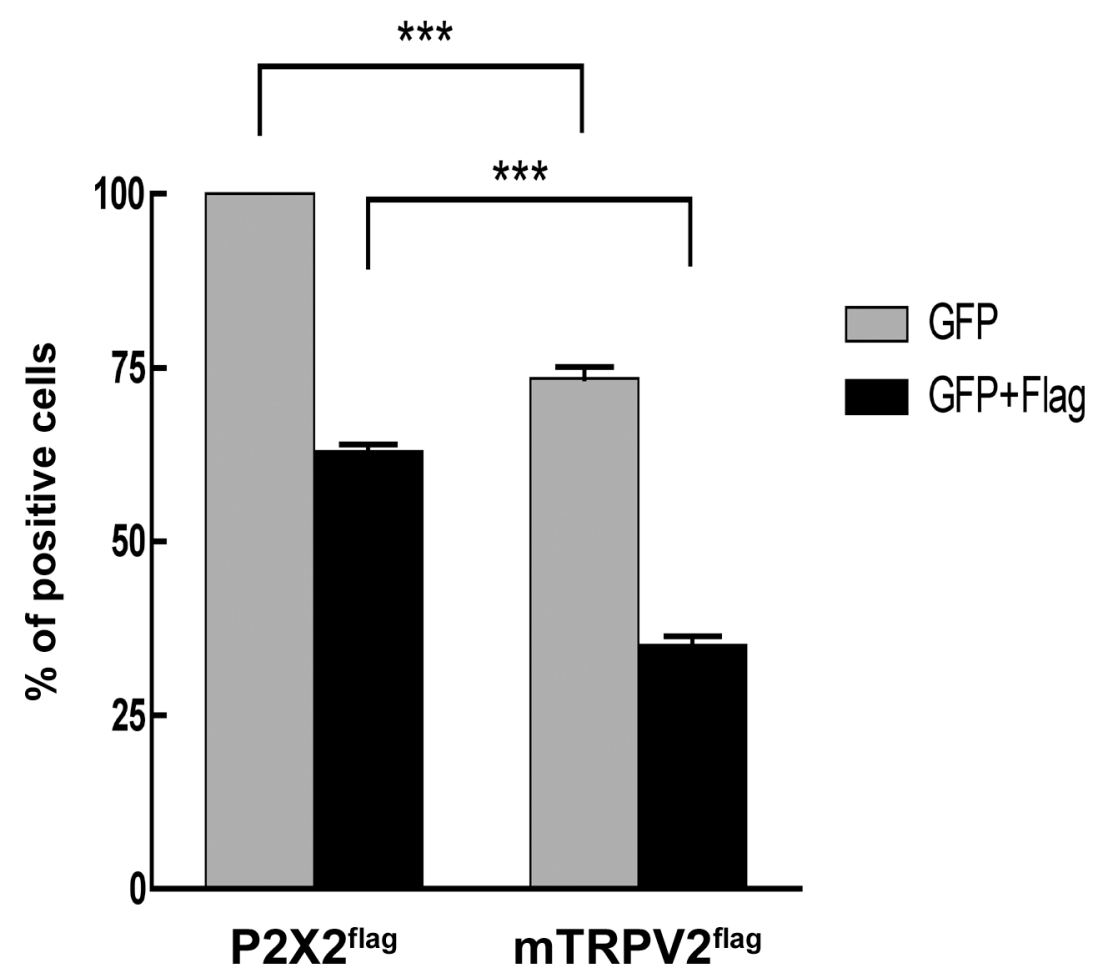

C

$P 2 \times 2^{\text {flag }}$

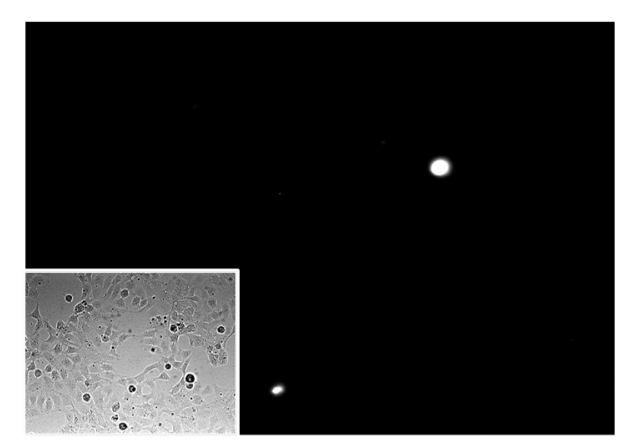

mTRPV2 $^{\text {flag }}$

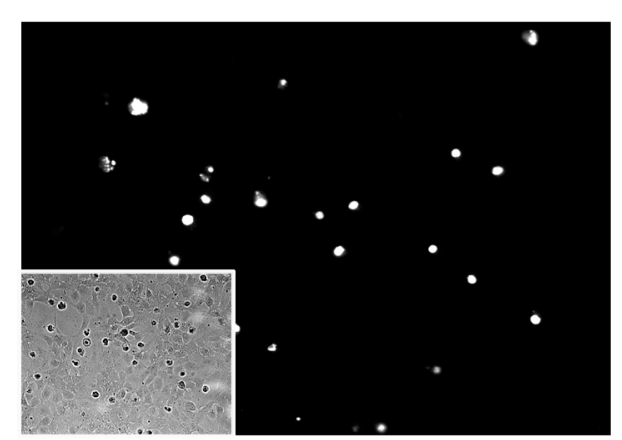

P2X7 + ATP

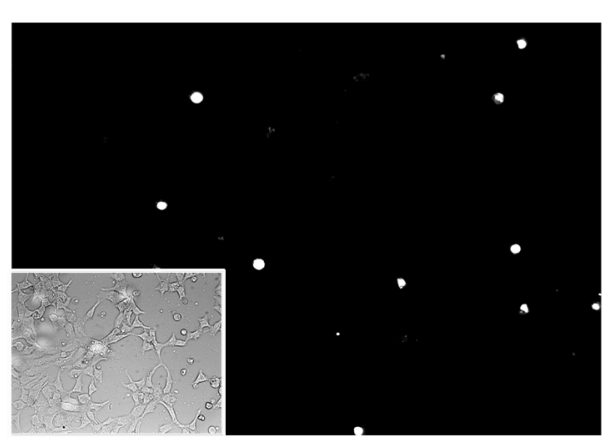




\section{Figure 2}

A

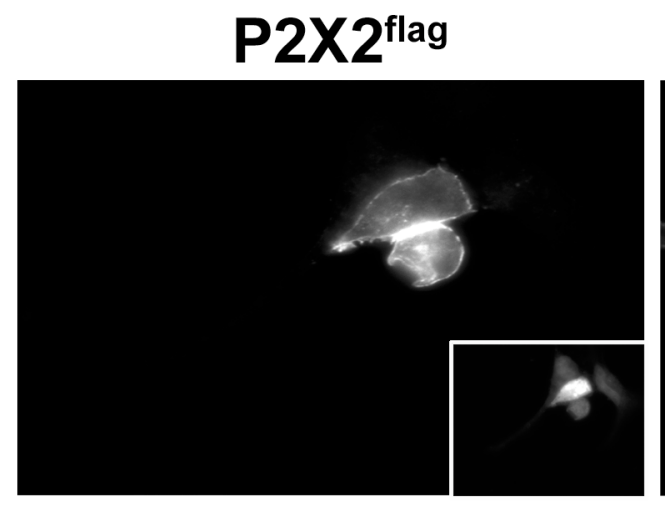
mTRPV2 ${ }^{\text {flag }}$ [E594K]

B
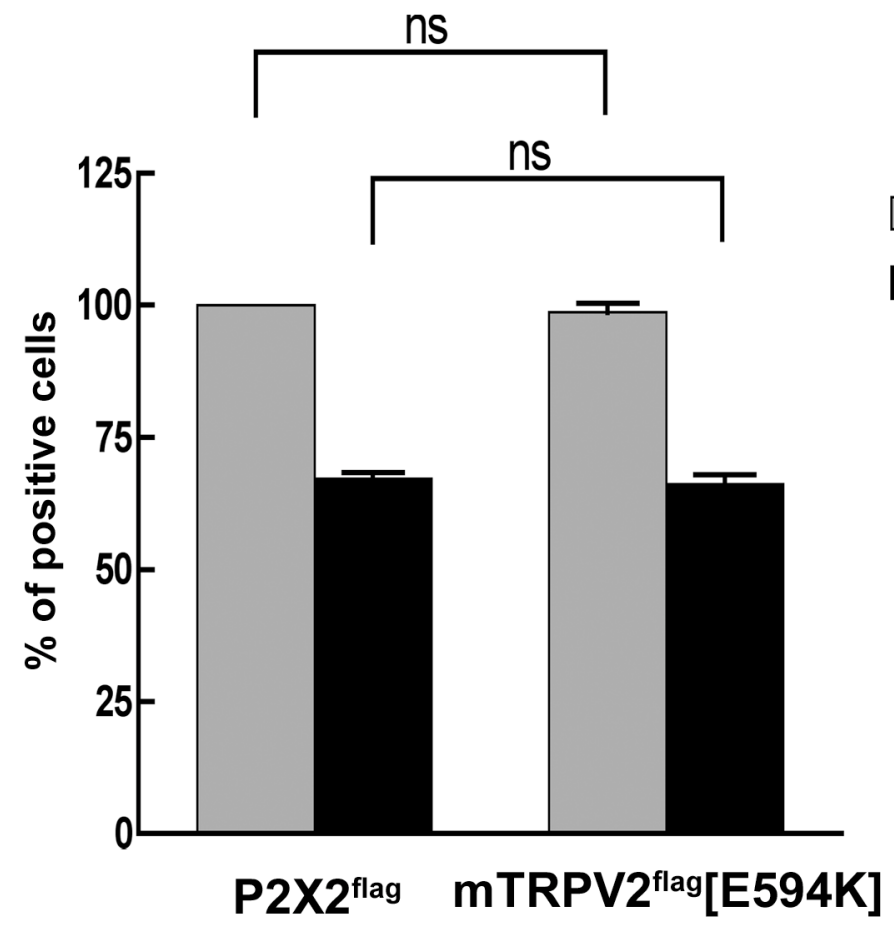

C

P2X2 flag

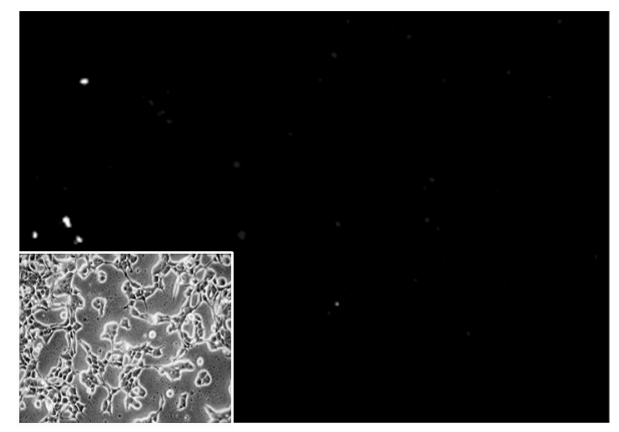

mTRPV2 ${ }^{\text {flag }}$ [E594K]

2

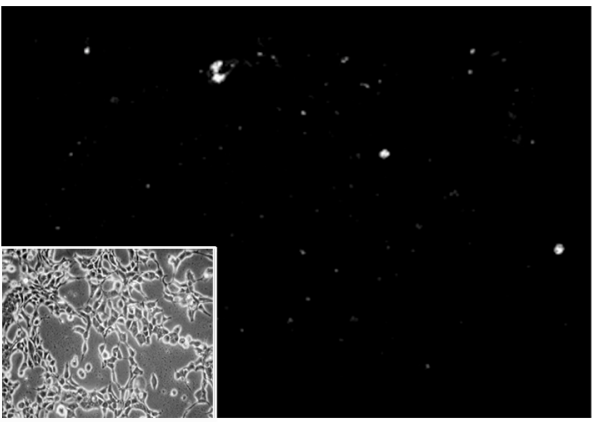

P2X7 + ATP

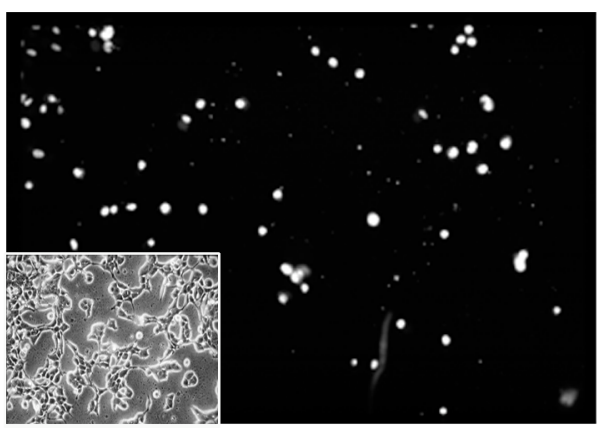


Figure 3

$\square$ GFP GFP+Flag

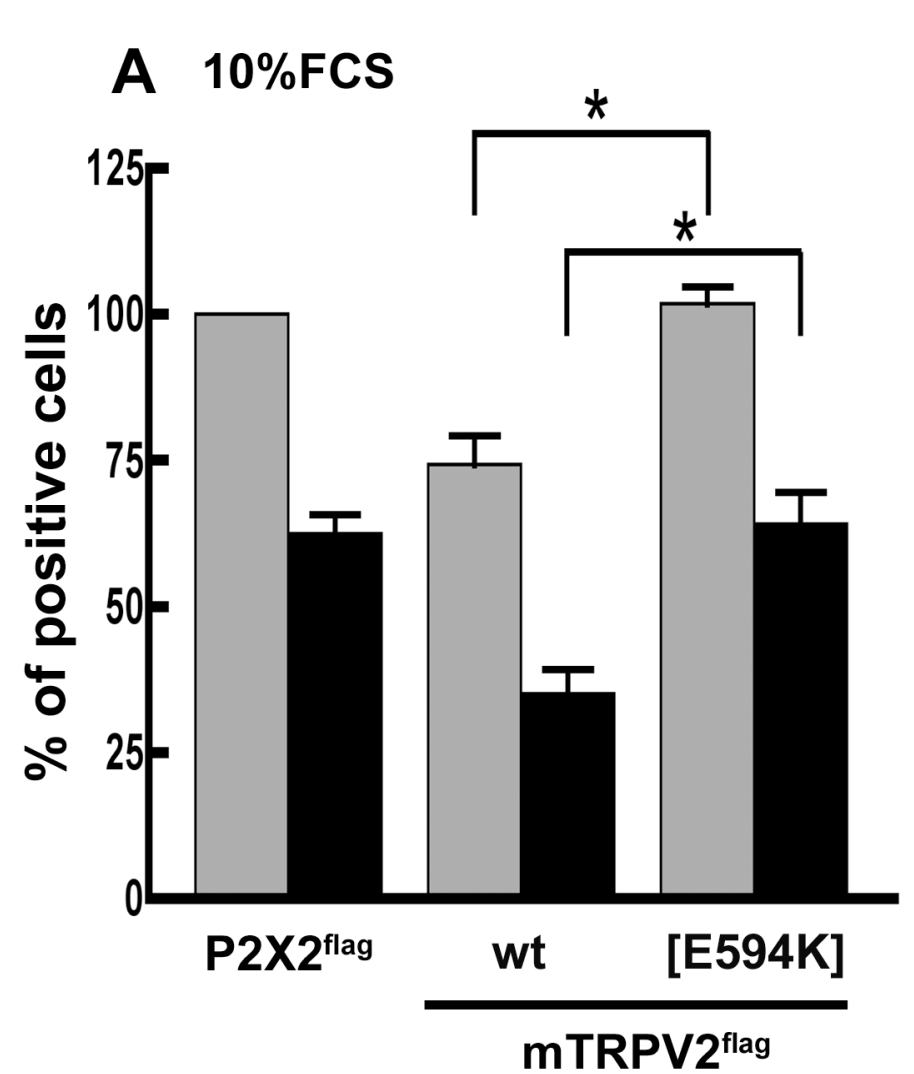

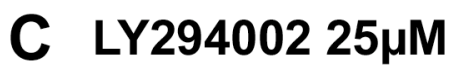

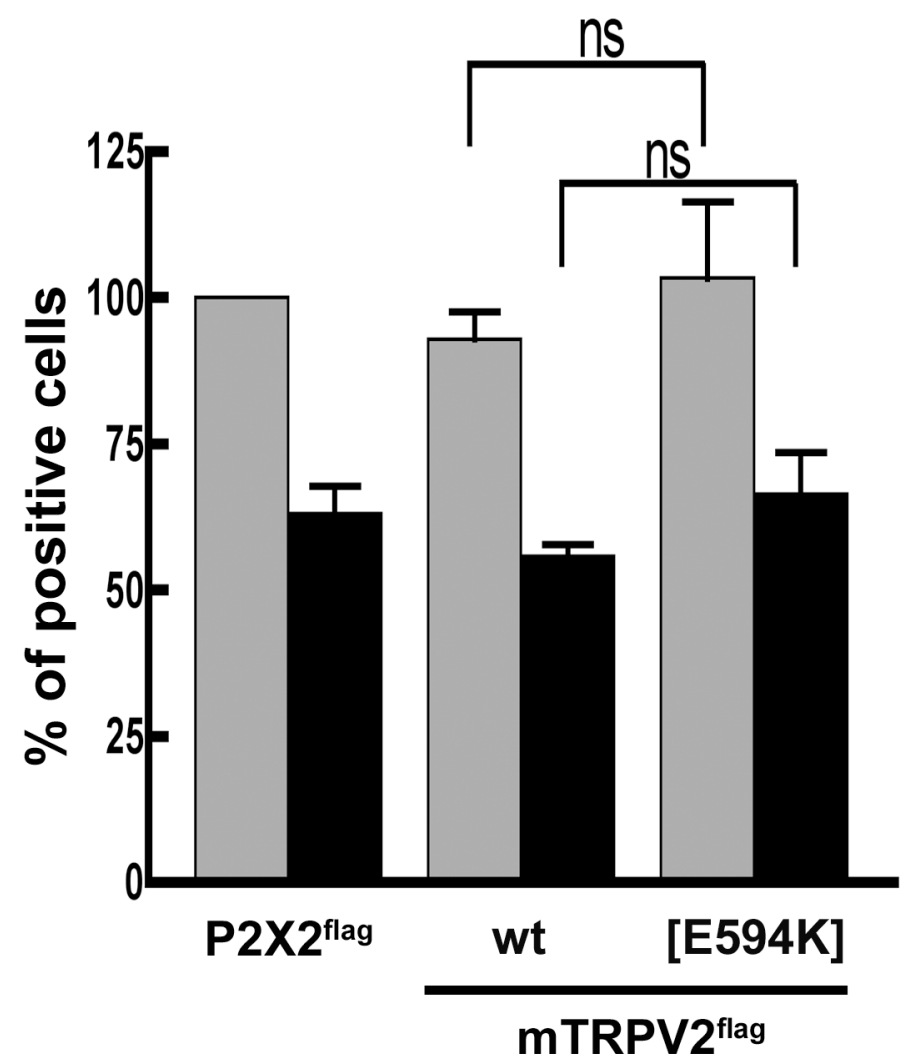

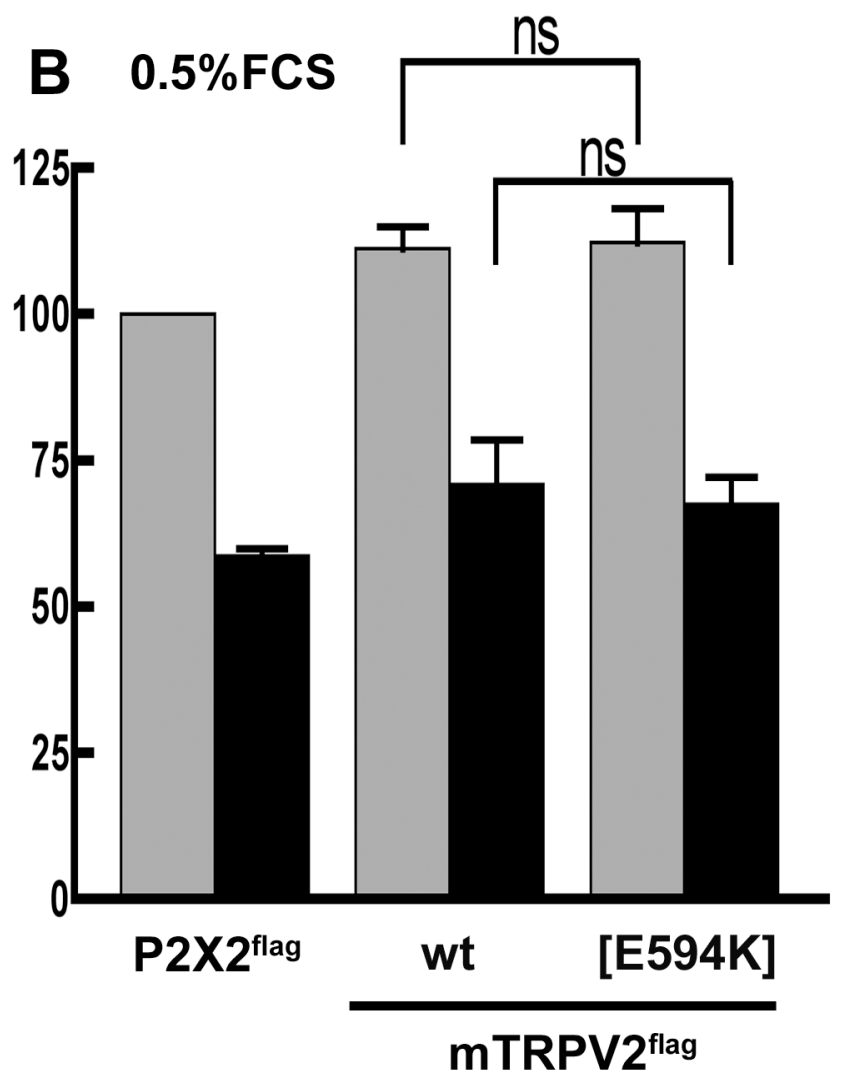

D EGTA $1.5 \mathrm{mM}$

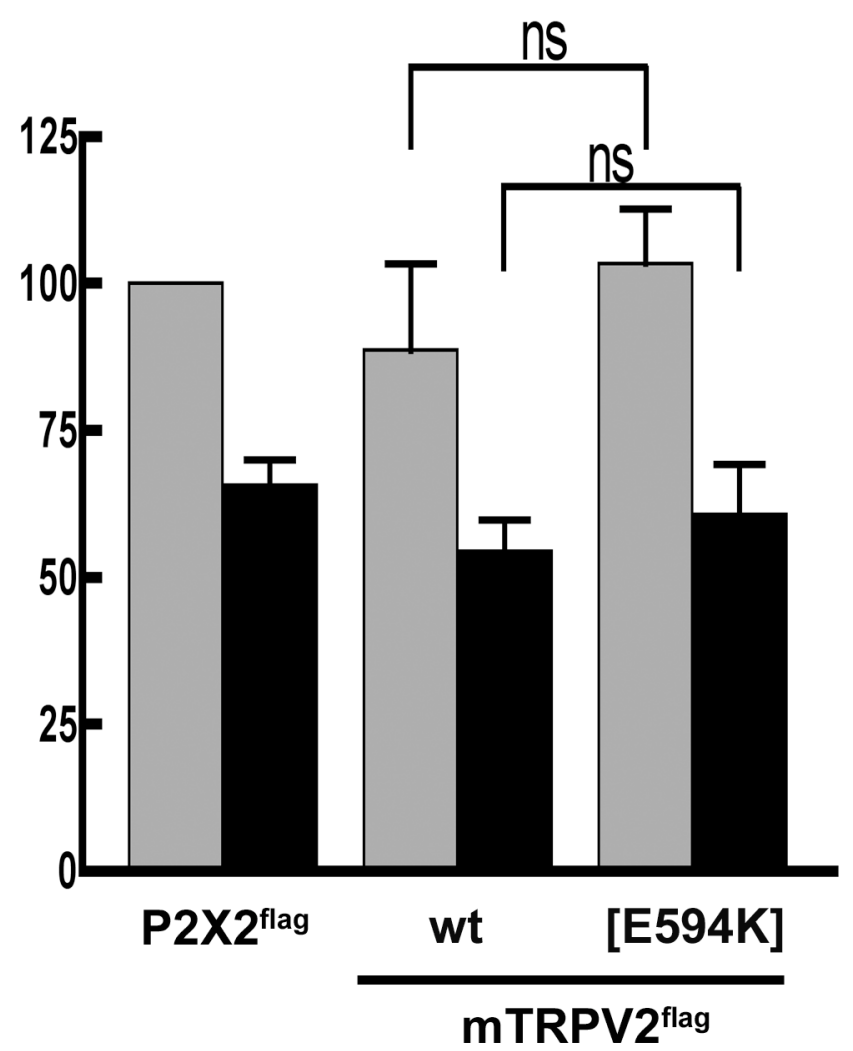




\section{Figure 4}
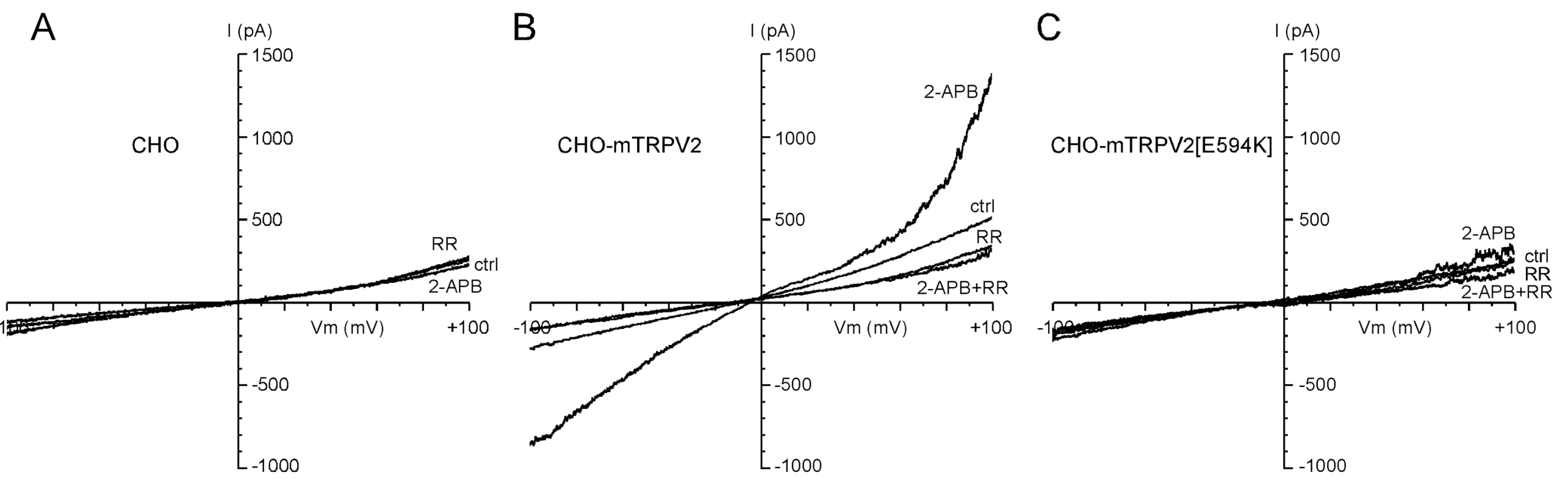

D

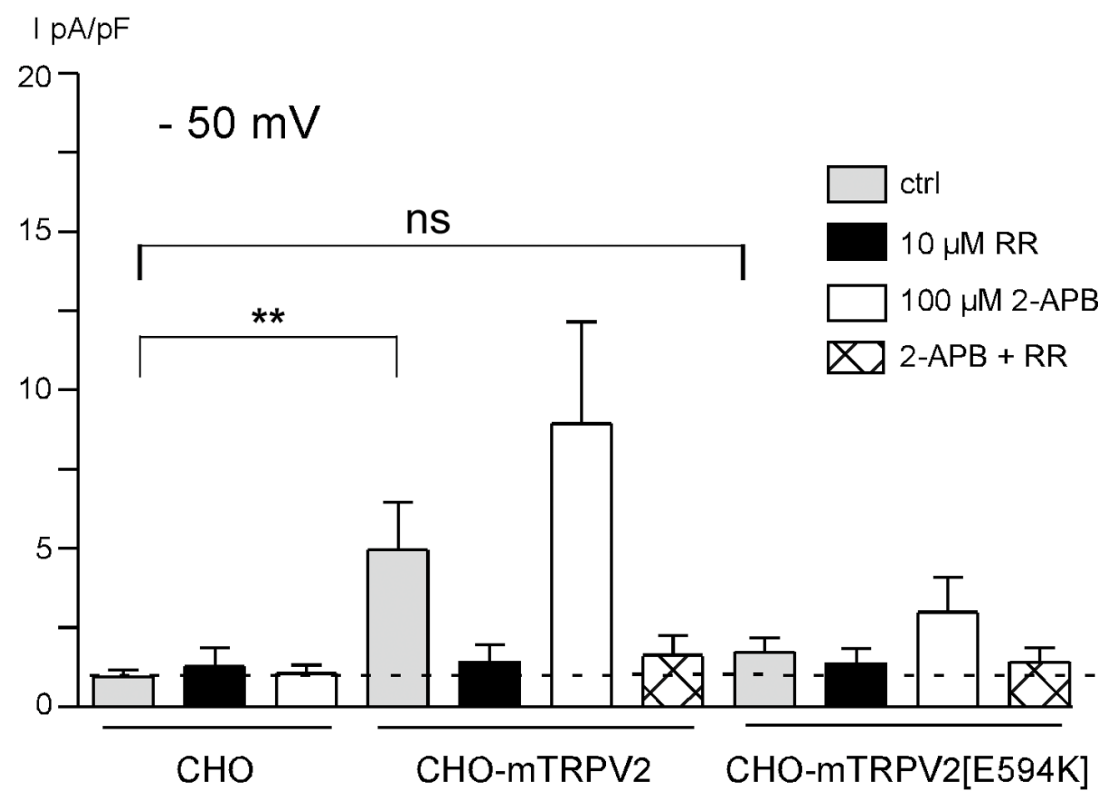

E

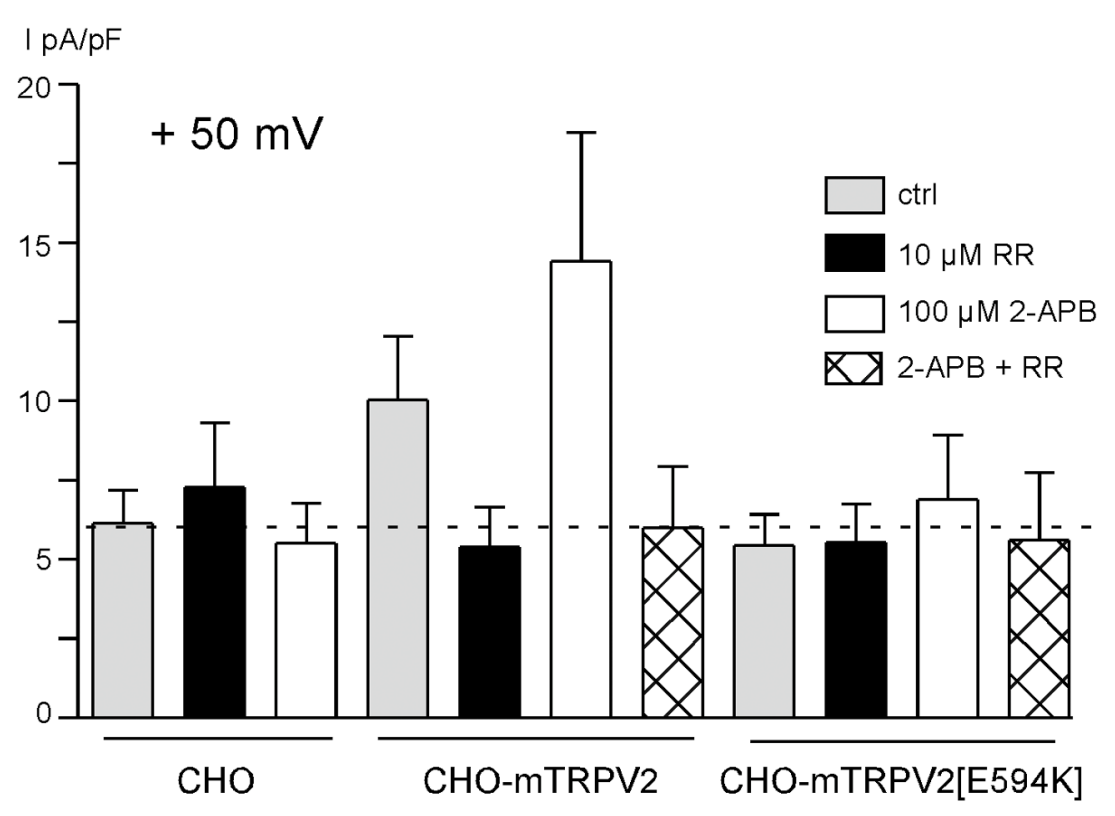




\section{Figure 5}

A

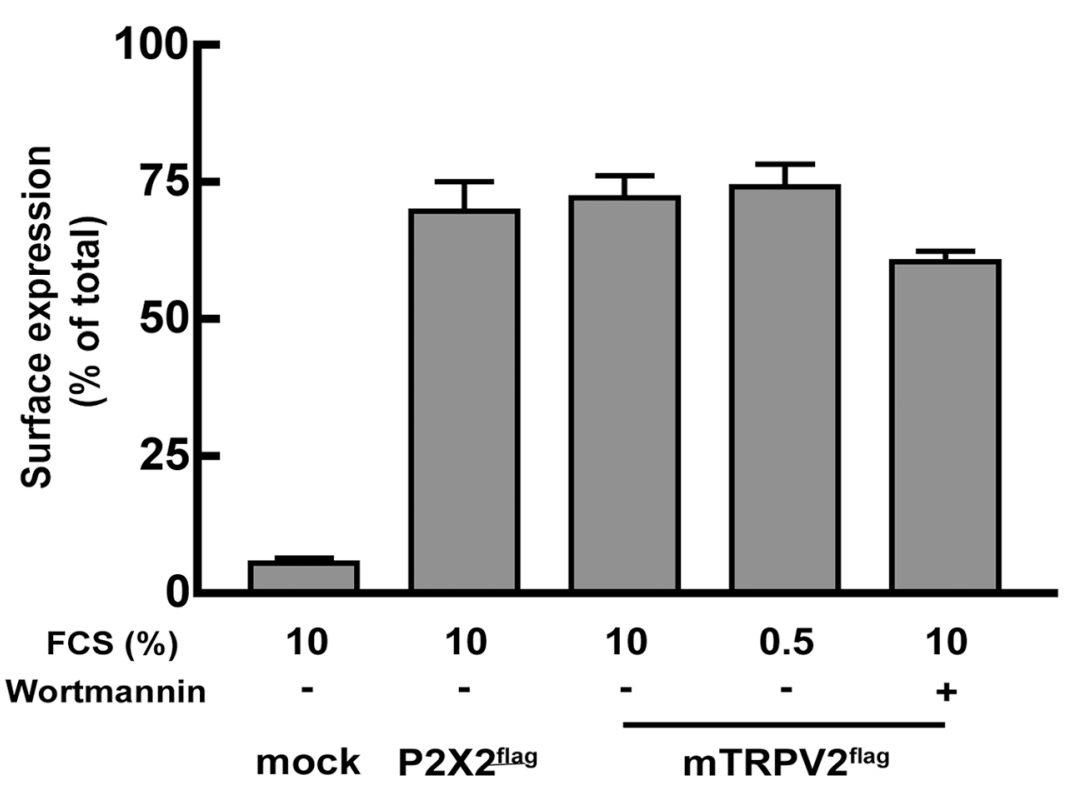

B CHO-mTRPV2
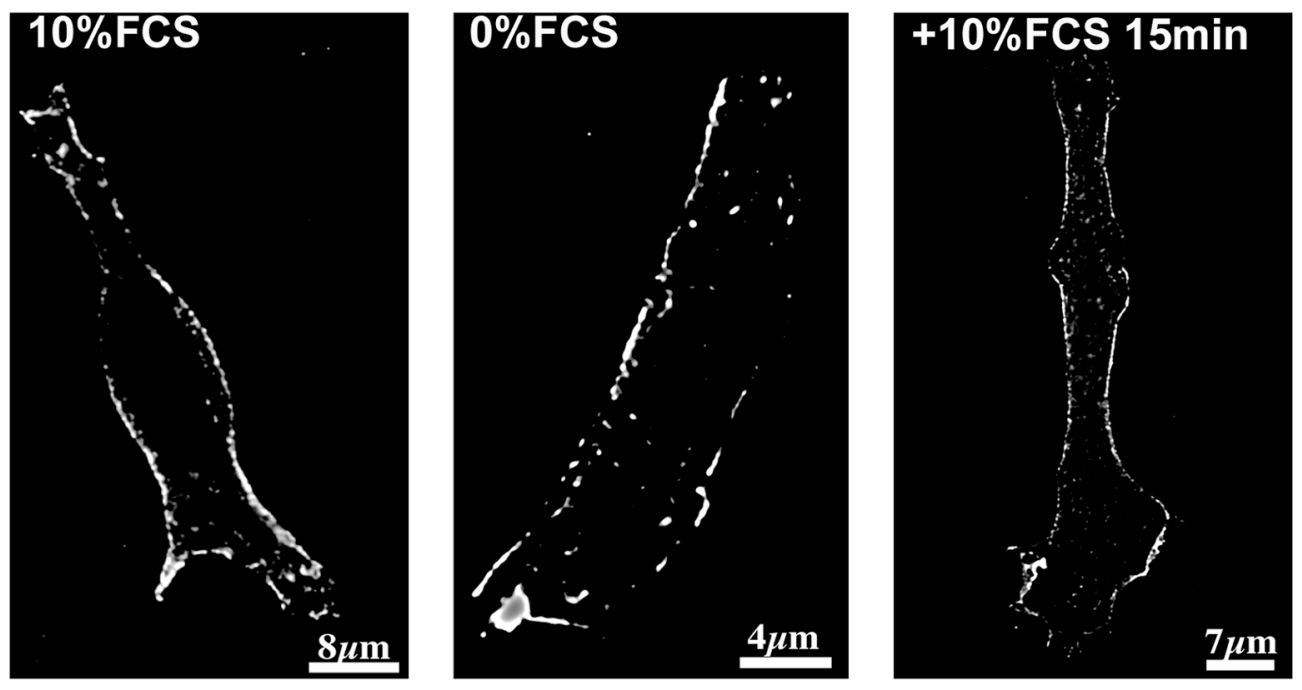

C
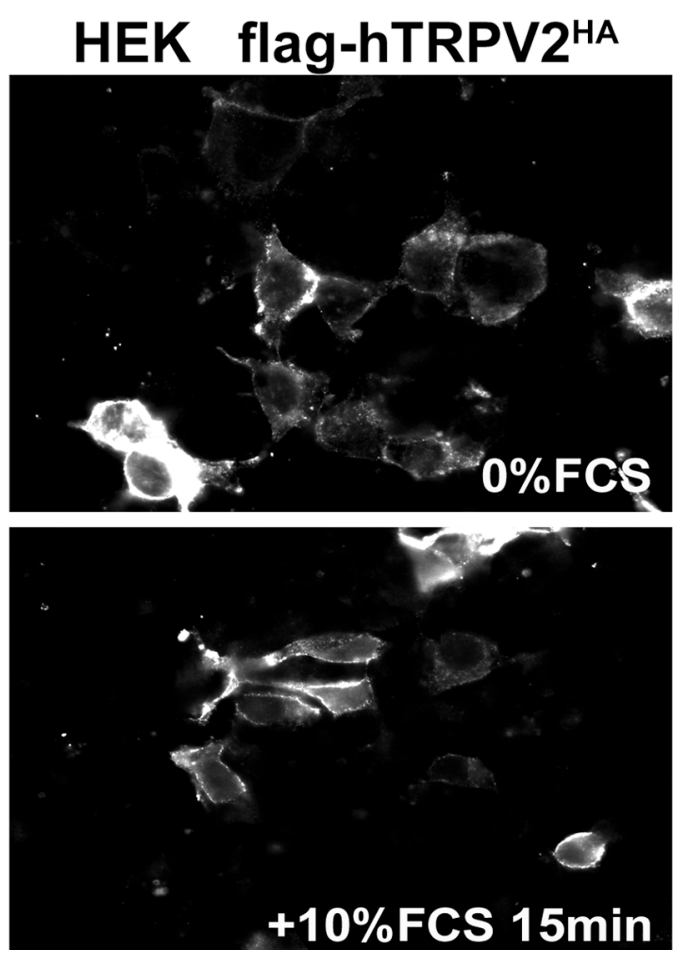

D

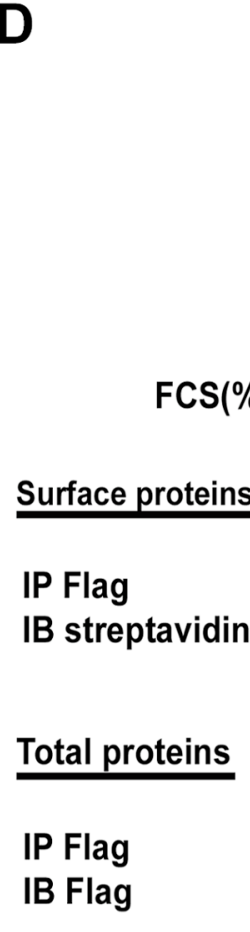

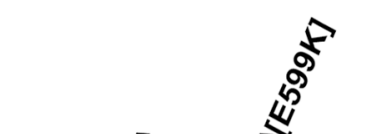

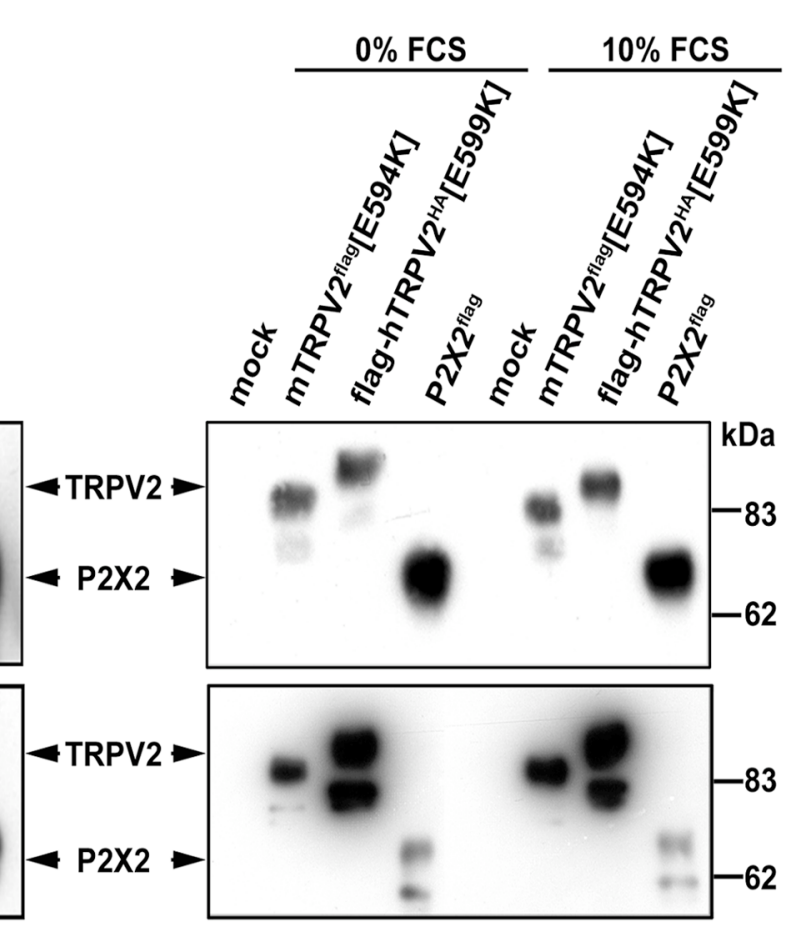

